\title{
Rapid Estimation of the Economic Consequences of Global Earthquakes
}

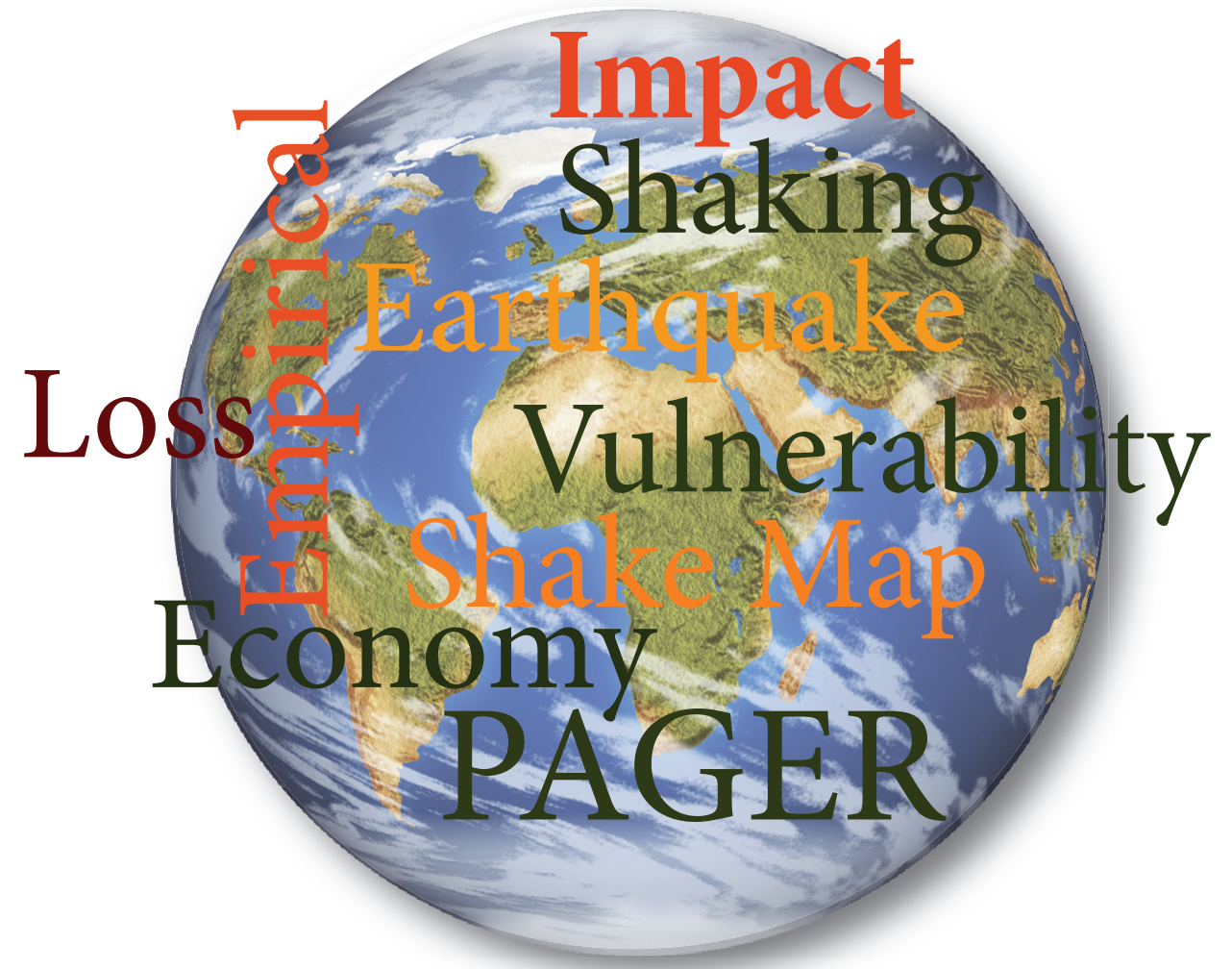

Open-File Report 2011-1116

U.S. Department of the Interior

U.S. Geological Survey 


\section{U.S. Department of the Interior KEN SALAZAR, Secretary}

\section{U.S. Geological Survey \\ Marcia K. McNutt, Director}

\section{U.S. Geological Survey, Reston, Virginia 2011}

\section{About USGS Products}

For product and ordering information:

World Wide Web: http://www.usgs.gov/pubprod

Telephone: 1-888-ASK-USGS

For more information on the USGS ---the Federal source for science about the Earth, its natural and living resources, natural hazards, and the environment:

World Wide Web: http://www.usgs.gov

Telephone: 1-888-ASK-USGS

\section{About this Product}

For more information concerning this publication, contact:

Center Director, USGS Central Region Geologic Hazards Science Center

Box 25046

Denver Federal Center

MS-966

Denver, CO 80225-0046

(303) $236-5344$

Or visit the Central Region Geologic Hazards Team Web site at:

http://earthquake.usgs.gov/

This publication is available online at:

http://earthquake.usgs.gov/pager

Publishing support provided by:

Denver Publishing Service Center, Denver, Colorado

Manuscript approved for publication, May 3, 2011

Edited by William J. Bryan

Authors designed the cover page graphic of this report. The background image that shows the space view of earth was taken from Microsoft Power Point clip art gallery, and the narrative text was designed using the website www.wordle.net

Suggested citation:

Jaiswal, K.S. and Wald, D.J., 2011, Rapid estimation of the economic consequences of global earthquakes: U.S. Geological Survey Open-File Report 2011-1116, 47 p.

Any use of trade, product, or firm names is for descriptive purposes only and does not imply endorsement by the U.S. Government. Although this report is in the public domain, permission must be secured from the individual copyright owners to reproduce any copyrighted material contained within this report. 


\section{Contents}

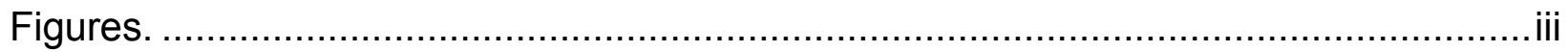

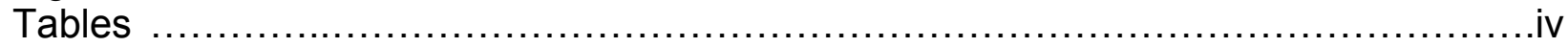

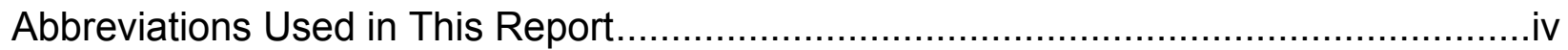

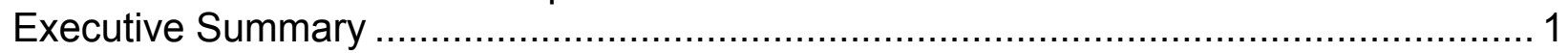

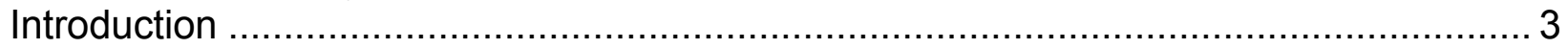

The Economic Consequences of Global Earthquakes............................................ 5

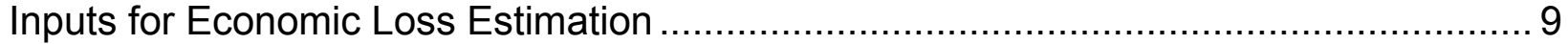

Atlas of ShakeMap and Population Exposure .................................................. 9

Atlas Estimate of per capita Gross Domestic Product ...................................... 9

Catalog of Economic Losses for Historical Earthquakes .................................. 10

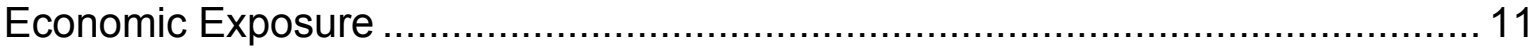

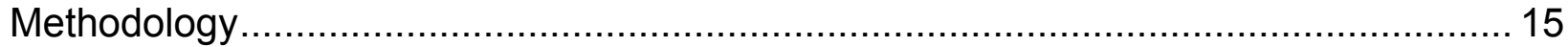

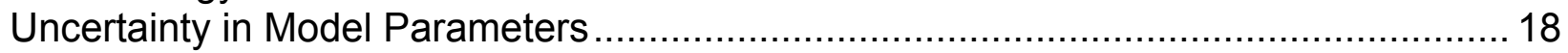

Estimating Fractiles of an Estimated Loss ................................................................. 19

Estimation of an Earthquake Alert Likelihood for low intensity earthquakes.......... 22

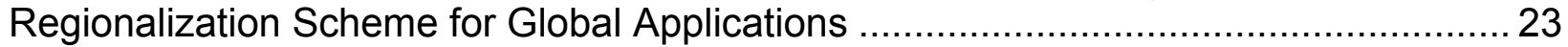

Human development index ................................................................ 23

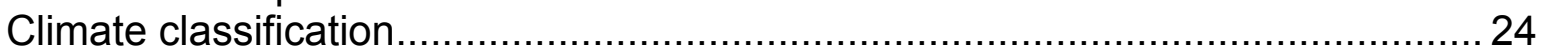

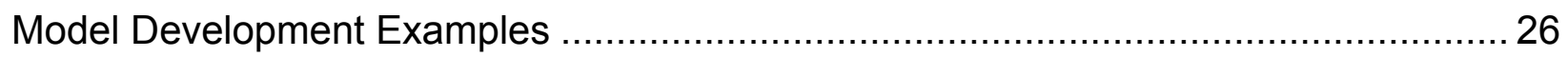

PAGER Implementation and Loss Estimation for Recent Earthquakes ......................... 33

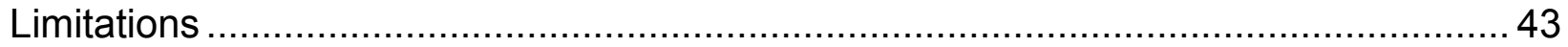

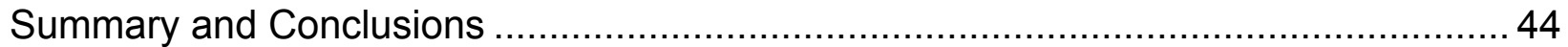

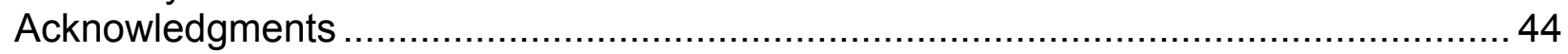

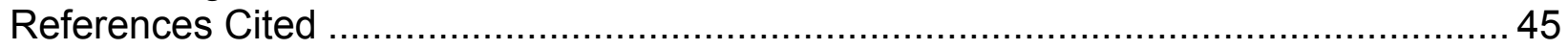

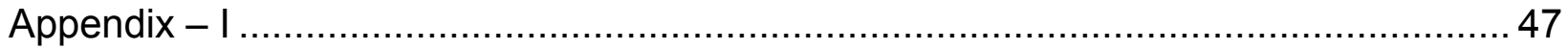




\section{Figures}

Figure 1. Economic consequences of global earthquakes between 1980 and 2008.

Figure 2. Fatality and economic loss distribution plots for earthquakes from 1980 to 2008 by country. Plots A \& C shows distribution of fatalities by countries with or without 2004 Indian Ocean tsunami losses respectively and plots B \& D shows such distributions for economic losses.

Figure 3. Probability distribution (for $E(L)=205, \zeta=1.2$ ) diagram showing estimates of probability of occurrence with different threshold levels of losses. (A), Cumulative probability estimates at certain thresholds of loss. (B), Histogram showing probability estimates at different thresholds.

Figure 4. Illustration of PAGER earthquake impact alert estimates.

Figure 5. Map showing USGS PAGER Empirical Model Regionalization classification (version 2.0: May 2010).

Figure 6. Diagram $(A)$ showing estimated vs. catalog recorded economic losses for historical earthquakes in Japan obtained using $(B)$ economic loss ratio as a function of shaking intensity $(\theta=10.29, \beta=0.1, \zeta=1.95)$.

Figure 7. (A) Diagram showing estimated vs. catalog recorded historical earthquake losses for Turkey obtained using $(B)$ economic loss ratio as a function of shaking intensity $(\theta=9.46, \beta=$ $0.1, \zeta=1.3)$.

Figure 8. (A) Diagram showing estimated vs. catalog recorded historical earthquake losses for Italy obtained using $(B)$ economic loss ratio as a function of shaking intensity $(\theta=9.03, \beta=0.1$, $\zeta=2.39$ ).

Figure 9. Regional model derived using earthquakes in Eastern South American countries (Brazil, Bolivia, Colombia, French Guiana, Guyana, Paraguay, Suriname, and Uruguay) showing the loss ratio as a function of shaking intensity $(\theta=8.42, \beta=0.1, \zeta=2.19)$.

Figure 10. Loss estimates produced by PAGER system (beta version) for the 2010 Haiti earthquake.

Figure 11. Loss estimates produced by operational PAGER system weeks after the 2010 Haiti earthquake using revised shaking hazard estimates with finite fault model.

Figure 12. Loss estimates produced by PAGER system (beta version) for the 2010 Chile earthquake.

Figure 13. Loss estimates produced by operational PAGER system weeks after the 2010 Chile earthquake using revised shaking hazard estimates with finite fault model.

Figure 14. Loss estimates produced by operational PAGER system after the 2010 Darfield, New Zealand, earthquake.

Figure 15. Loss estimates produced by operational PAGER system weeks after the 2010 Darfield, New Zealand, earthquake using revised shaking hazard estimates with finite fault model. 


\section{Tables}

Table 1. List of countries showing direct economic losses and total fatalities as the result of earthquakes and related disasters (such as tsunami, landslide, fire, and liquefaction) recorded from 1980 to 2008.

Table 2. Munich Re's total direct economic loss data for selected events (Source: NatCat Service 1980-2008).

Table 3. Estimating exposure correction factor using GDP and wealth data for selected countries.

Table 4. Empirical model parameters for selected countries.

\section{Abbreviations Used in This Report}

ISO International Standards Organization

EIS Earthquake Impact Scale

EXPO-CAT Exposure Catalog

FEMA Federal Emergency Management Agency

GDP gross domestic product

GEM Global Earthquake Model

HAZUS Hazard US (FEMA Loss Estimation Software)

HDI human development index

IMF International Monetary Fund

MMI Modified Mercalli Intensity

OCHA Office of the Coordination of Humanitarian Affairs

PAGER Prompt Assessment of Global Earthquakes for Response

PGA peak ground acceleration

PGV peak ground velocity

PSA peak spectral acceleration

UNSD United Nations Statistical Division

US United States

USAID United States Agency for International Development

USGS U.S. Geological Survey

USD United States Dollar 


\section{Rapid Estimation of the Economic Consequences}

\section{of Global Earthquakes}

By Kishor Jaiswal ${ }^{1}$ and David J. Wald ${ }^{2}$

\section{Executive Summary}

The U.S. Geological Survey’s (USGS) Prompt Assessment of Global Earthquakes for Response (PAGER) system, operational since mid 2007, rapidly estimates the most affected locations and the population exposure at different levels of shaking intensities. The PAGER system has significantly improved the way aid agencies determine the scale of response needed in the aftermath of an earthquake. For example, the PAGER exposure estimates provided reasonably accurate assessments of the scale and spatial extent of the damage and losses following the 2008 Wenchuan earthquake (Mw 7.9) in China, the 2009 L'Aquila earthquake (Mw 6.3) in Italy, the 2010 Haiti earthquake (Mw 7.0), and the 2010 Chile earthquake (Mw 8.8).

Nevertheless, some engineering and seismological expertise is often required to digest PAGER's exposure estimate and turn it into estimated fatalities and economic losses. This has been the focus of PAGER's most recent development.

\footnotetext{
${ }^{1}$ U.S. Geological Survey, P.O. Box 25046, M.S. 966, Denver, CO 80225-0046 (contracted through Synergetics Incorporated).

${ }^{2}$ U.S. Geological Survey, P.O. Box 25046, M.S. 966, Denver, CO 80225-0046.
} 
With the new loss-estimation component of the PAGER system it is now possible to produce rapid estimation of expected fatalities for global earthquakes (Jaiswal and others, 2009). While an estimate of earthquake fatalities is a fundamental indicator of potential human consequences in developing countries (for example, Iran, Pakistan, Haiti, Peru, and many others), economic consequences often drive the responses in much of the developed world (for example, New Zealand, the United States, and Chile), where the improved structural behavior of seismically resistant buildings significantly reduces earthquake casualties.

Rapid availability of estimates of both fatalities and economic losses can be a valuable resource. The total time needed to determine the actual scope of an earthquake disaster and to respond effectively varies from country to country. It can take days or sometimes weeks before the damage and consequences of a disaster can be understood both socially and economically. The objective of the U.S. Geological Survey's PAGER system is to reduce this time gap to more rapidly and effectively mobilize response.

We present here a procedure to rapidly and approximately ascertain the economic impact immediately following a large earthquake anywhere in the world. In principle, the approach presented is similar to the empirical fatality estimation methodology proposed and implemented by Jaiswal and others (2009). In order to estimate economic losses, we need an assessment of the economic exposure at various levels of shaking intensity. The economic value of all the physical assets exposed at different locations in a given area is generally not known and extremely difficult to compile at a global scale. In the absence of such a dataset, we first estimate the total Gross Domestic Product (GDP) exposed at each shaking intensity by multiplying the per-capita GDP of the country by the total population exposed at that shaking intensity level. We then scale the total GDP estimated at each intensity by an exposure correction factor, which is a multiplying factor to 
account for the disparity between wealth and/or economic assets to the annual GDP. The economic exposure obtained using this procedure is thus a proxy estimate for the economic value of the actual inventory that is exposed to the earthquake. The economic loss ratio, defined in terms of a country-specific lognormal cumulative distribution function of shaking intensity, is derived and calibrated against the losses from past earthquakes. This report describes the development of a country or region-specific economic loss ratio model using economic loss data available for global earthquakes from 1980 to 2007 . The proposed model is a potential candidate for directly estimating economic losses within the currently-operating PAGER system. PAGER's other loss models use indirect methods that require substantially more data (such as building/asset inventories, vulnerabilities, and the asset values exposed at the time of earthquake) to implement on a global basis and will thus take more time to develop and implement within the PAGER system.

\section{Introduction}

Accurate estimation of earthquake-induced economic losses depends upon several different factors and their complex interdependencies. Detailed damage and loss analyses require a number of ingredients; for example, an inventory of building and infrastructure exposure; the buildings' relative vulnerability to ground shaking; an assessment of socio-economic wealth associated with the exposed assets; and an understanding of the region's productivity, economic growth, and resiliency. Compilation of such factors at a global scale is a mammoth task in itself, and despite the availability of data for certain parts of the world, the knowledge and tools are often unavailable to perform quantitative risk and loss analyses. In addition, the availability of required data and models does not ensure useful loss estimates unless the estimates are calibrated against historical 
earthquake losses. Furthermore, the true cost of an earthquake is rarely known until years later (Seligson and Eguchi, 2005), and is often poorly determined for many past earthquakes.

Previous researchers have attempted to simplify the problem of economic loss analysis using a macroseismic or macroeconomic-based empirical approach. For example, Chan and others (1998) combined population and GDP data with knowledge of the seismic hazard and published earthquake loss data to estimate earthquake loss. Dunbar and others (2002) used a similar approach for evaluating seismic risk and loss in India using historical earthquake data recorded between 1990 and 2001. Chen and others (2001) performed economic loss assessment for Hong Kong using a macroseismic approach. A recent macroeconomic-based approach includes a global risk map for mortality and economic losses for six major natural hazards (including earthquakes) created by Columbia University under the umbrella of the ProVention Consortium of the World Bank (Dilley and others, 2005).

An example of a direct physical loss estimation method that includes an estimate of both direct (building damage, content damage, and business interruption) and indirect losses (effects on economic sectors incurred over a time interval) to building and infrastructure inventory is the procedure implemented within the HAZUS software (Brookeshire and others, 1997; Federal Emergency Management Agency, 2006). The economic loss estimated using such a procedure in the aftermath of an earthquake highlights the amount of investment needed to retrofit or replace damaged infrastructure.

This report details a new indirect procedure to rapidly estimate the economic loss in the aftermath of a damaging earthquake. The procedure consists of estimating the country or regionspecific economic loss ratio, which varies as a function of shaking intensity and is calibrated against historical earthquake losses. At the heart of the approach is an approximation of economic 
exposure using population data, GDP, and a regional correction factor. This approach bypasses the requirement of detailed building-inventory datasets, which may or may not be available for certain parts of the world. We discuss various ingredients necessary for economic loss estimation and document the methodology for deriving the economic loss-ratio function. Further, we illustrate the economic loss estimation for selected countries and demonstrate its suitability within the U.S.

Geological Survey's PAGER system.

\section{The Economic Consequences of Global Earthquakes}

Globally, earthquakes claimed close to 600,000 lives and caused over 400 billion United States Dollars (USD) in economic loss from 1980 to 2008 (Source: Munich Re's catalog, NatCatSERVICE, 2008). Economic losses averaged around 5 billion USD a year until the 1994 Northridge earthquake and then nearly quintupled to 24 billion USD a year due to the occurrence of a series of large earthquakes around the world (for example, Northridge 1994, Kobe 1995, Izmit 1999, Chi Chi 1999, Indonesia 2004, and Wenchuan 2008). These are evident in the distinct spikes in the diagram in Figure 1, which shows annual economic losses globally during the last 29 years and a two-year moving-average trend line. Global averages such as those shown with a trend line in Figure 1 are not indicative of average economic risk of the world as they are often strongly influenced when large, consequential earthquakes occur. 


\section{Economic Losses Due to Earthquakes}

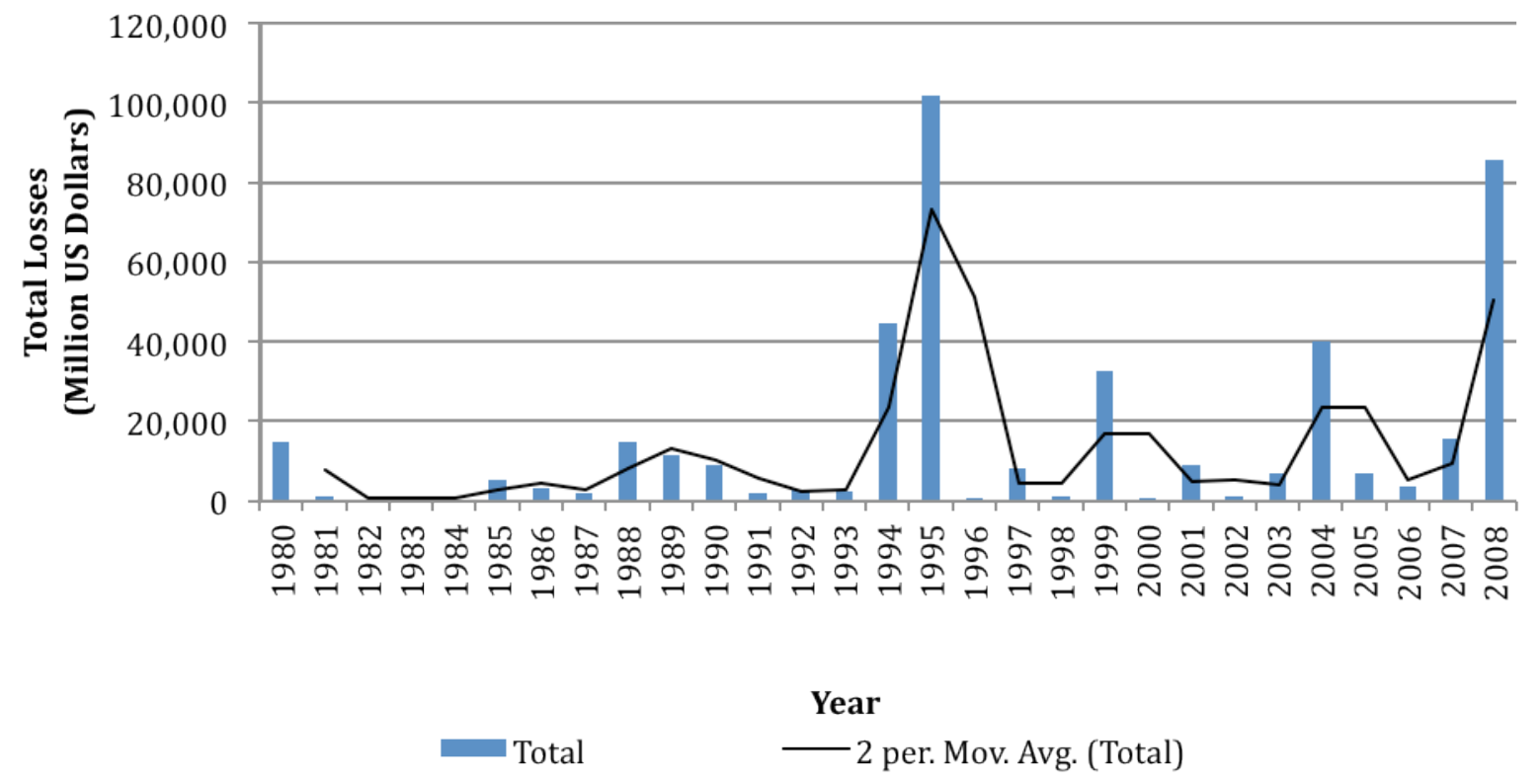

Figure 1. Economic consequences of global earthquakes between 1980 and 2008. Economic losses are the original estimates recorded at the time of the earthquake and they are not adjusted for inflation or today's value of US dollars.

Table 1 provides the list of 48 countries, which cover close to 99 percent of the total recorded economic losses and total fatalities globally reported from 1980 to 2008 according to the Munich Re catalog (NatCatSERVICE, 2008). Table 1 shows that the countries vulnerable to economic loss are not necessarily the same countries that are vulnerable to life loss. 
Table 1. List of countries showing direct economic losses and total fatalities as the result of earthquakes and related disasters (such as tsunami, landslide, fire, and liquefaction) recorded from 1980 to 2008.

\begin{tabular}{|c|c|c|}
\hline Countries & $\begin{array}{c}\text { Direct Losses } \\
\text { in million } \\
\text { USD }\end{array}$ & Total Deaths \\
\hline Japan & 146,143 & 6,915 \\
\hline China & 89,040 & 71,745 \\
\hline United States & 57,418 & 154 \\
\hline Italy & 19,005 & 2,999 \\
\hline Turkey & 14,103 & 20,515 \\
\hline Taiwan & 14,060 & 2,415 \\
\hline Armenia & 14,004 & 25,045 \\
\hline Indonesia & $\begin{array}{c}9,151 \\
(\sim 4,652)\end{array}$ & $\begin{array}{c}171,987 \\
(11,987)\end{array}$ \\
\hline Iran & 9,003 & 74,515 \\
\hline India & $\begin{array}{c}8,496 \\
(5,996)\end{array}$ & $\begin{array}{c}43,412 \\
(27,112)\end{array}$ \\
\hline Algeria & 8,034 & 5,036 \\
\hline Greece & 7,045 & 246 \\
\hline Pakistan & 5,284 & 87,004 \\
\hline Mexico & 4,095 & 9,986 \\
\hline El Salvador & 3,091 & 2,170 \\
\hline Colombia & 2,216 & 1,861 \\
\hline Georgia & 2,059 & 287 \\
\hline Chile & 1,492 & 243 \\
\hline Australia & 1,279 & 14 \\
\hline Egypt & 1,201 & 576 \\
\hline Ecuador & 1,105 & 1,045 \\
\hline Peru & 1,027 & 1,029 \\
\hline Philippines & 1,021 & 1,819 \\
\hline Thailand & $\begin{array}{l}1,001 \\
(0.57)\end{array}$ & $\begin{array}{c}8,200 \\
(0)\end{array}$ \\
\hline
\end{tabular}

\begin{tabular}{|c|c|c|}
\hline Countries & $\begin{array}{l}\text { Direct Losses } \\
\text { in million } \\
\text { USD }\end{array}$ & Total Deaths \\
\hline Sri Lanka & $\begin{array}{c}1,000 \\
(0)\end{array}$ & $\begin{array}{c}35,300 \\
(0)\end{array}$ \\
\hline $\begin{array}{c}\text { Republic of } \\
\text { Moldova }\end{array}$ & 759 & 15 \\
\hline $\begin{array}{c}\text { Russian } \\
\text { Federation }\end{array}$ & 688 & 1,994 \\
\hline New Zealand & 587 & 4 \\
\hline Bangladesh & $\begin{array}{c}502 \\
(2.13)\end{array}$ & $\begin{array}{c}41 \\
(39)\end{array}$ \\
\hline Myanmar & $\begin{array}{c}500 \\
(0.45)\end{array}$ & $\begin{array}{l}90 \\
(0)\end{array}$ \\
\hline Maldives & $\begin{array}{c}500 \\
(0.02)\end{array}$ & $\begin{array}{l}100 \\
(0)\end{array}$ \\
\hline Malaysia & $\begin{array}{c}500 \\
(0.02) \\
\end{array}$ & $\begin{array}{l}70 \\
(2) \\
\end{array}$ \\
\hline Guam & 455 & - \\
\hline Morocco & 401 & 648 \\
\hline Croatia & 280 & 1 \\
\hline Nepal & 260 & 804 \\
\hline Kyrgyzstan & 178 & 195 \\
\hline Netherlands & 156 & - \\
\hline Afghanistan & 144 & 13,443 \\
\hline Costa Rica & 129 & 96 \\
\hline Germany & 124 & - \\
\hline Portugal & 112 & 67 \\
\hline $\begin{array}{c}\text { United } \\
\text { Kingdom }\end{array}$ & 110 & - \\
\hline Kenya & $\begin{array}{c}100 \\
(0.06) \\
\end{array}$ & $\begin{array}{c}1 \\
(0) \\
\end{array}$ \\
\hline Iceland & 100 & - \\
\hline Somalia & $\begin{array}{c}100 \\
(0.01)\end{array}$ & $\begin{array}{l}289 \\
(0)\end{array}$ \\
\hline Seychelles & $\begin{array}{l}100 \\
(0)\end{array}$ & $\begin{array}{c}2 \\
(0)\end{array}$ \\
\hline $\begin{array}{l}\text { Republic of } \\
\text { Yemen }\end{array}$ & 90 & 3,010 \\
\hline
\end{tabular}

Note: The numbers in brackets indicate total earthquake losses for a country when the 2004 Indian Ocean tsunami losses were excluded.

Figure 2 provides the proportion of total direct economic losses and fatalities worldwide, by country. Japan, China, and the United States dominate the total direct economic loss 
distribution from 1980 to 2008. Indonesia, Pakistan, China, and Iran sustained most of the fatalities. Further, no correlation between a country's vulnerability to life loss and its economic loss is applicable worldwide. Hence, a comprehensive loss estimation system must address both facets of earthquake impacts.

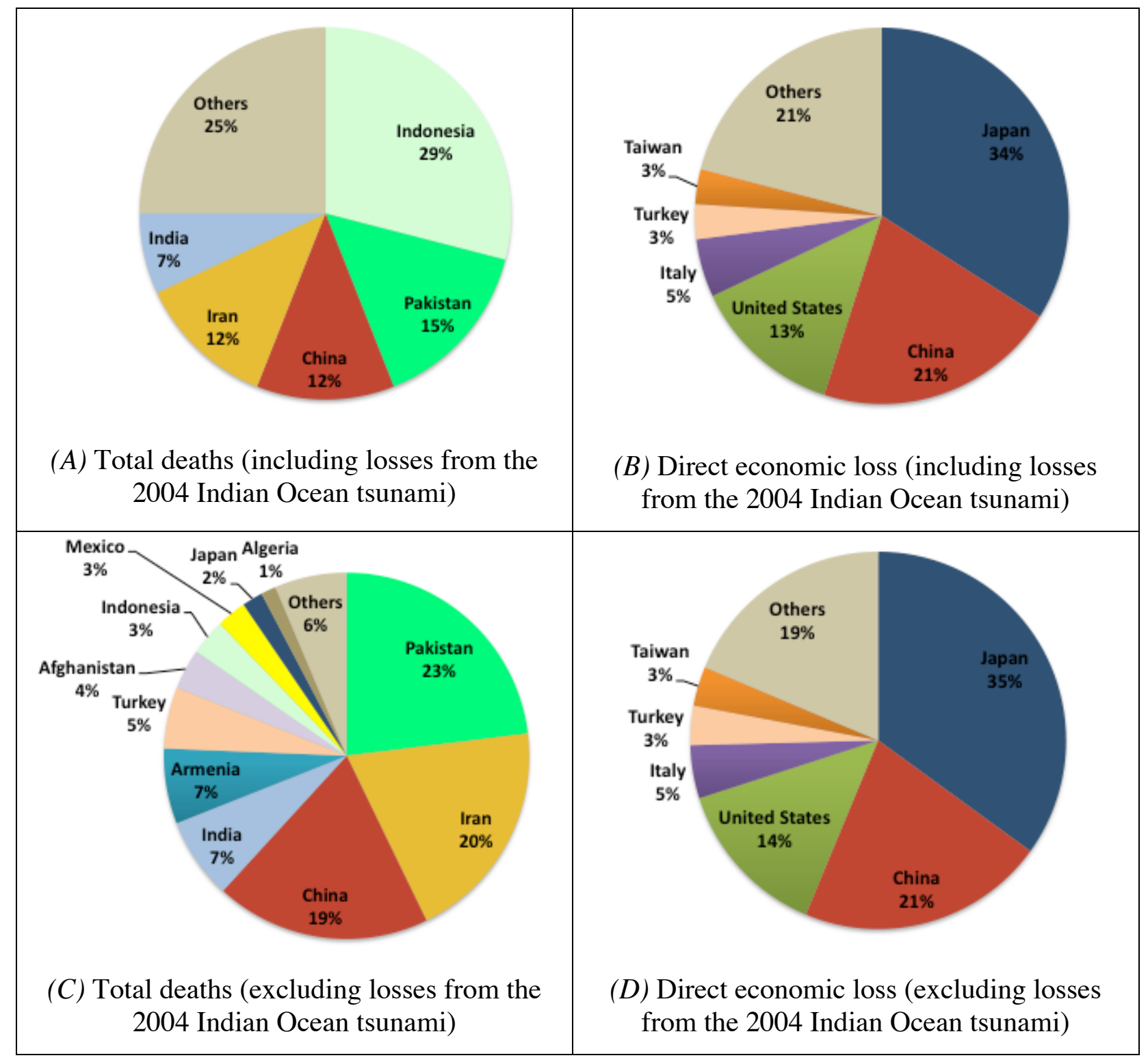

Figure 2. Fatality and economic loss distribution plots for earthquakes from 1980 to 2008 by country. Plots A \& C shows distribution of fatalities by countries with or without 2004 Indian Ocean tsunami losses respectively and plots B \& D shows such distributions for economic losses. 
Note that since the beginning of 2010 these statistics will have changed dramatically due to recent earthquakes in Haiti, Chile, and China, each of which caused social and economic disruption on a large scale. At the time of this writing, earthquake fatalities and economic losses for some of the recent earthquakes were not yet available.

\section{Inputs for Economic Loss Estimation}

The indirect approach for economic loss estimation and its calibration are outlined below.

\section{Atlas of ShakeMap and Population Exposure}

In order to develop and validate earthquake losses within the USGS PAGER program, a catalog of historical earthquakes containing spatial distribution of earthquake shaking and the estimated population exposed to each shaking intensity level is needed. Allen and others (2009a) compiled an exposure catalog referred to as EXPO-CAT by combining an Atlas of ShakeMaps (1973-2007) and the LandScan population database (Bhaduri and others, 2002). The EXPO-CAT catalog contains an estimate of population exposure at discrete shaking intensity levels obtained using PAGER methodology (Wald and others, 2008). EXPO-CAT population exposure estimates, although derived from 2008 LandScan population data, are already corrected for the year of the earthquake using negative population growth factors. The catalog and its documentation with updates can be readily accessed at the PAGER Web page (http://earthquake.usgs.gov/eqcenter/pager/prodandref/).

\section{Atlas Estimate of per capita Gross Domestic Product}

The Gross Domestic Product (GDP) of a region or country is a useful and readily available indicator for estimating economic development within a region. It represents a region's 
productivity (that is, newly created wealth), and is often positively correlated with the standard of living. Chan and others (1998) analyzed the seismic losses between high, middle, and low-income nations, and found a strong correlation between GDP and known seismic losses. The GDP dataset is compiled from several different agencies including the World Bank, the United Nations, and the International Monetary Fund (IMF).

The Economic Statistics Branch of the United Nations Statistics Division (UNSD) maintains and annually updates the National Accounts Main Aggregates database. These data are compiled from the official data reported to UNSD through the annual National Accounts Questionnaire, supplemented by data estimates for any years and countries with incomplete or inconsistent information (http://unstats.un.org/unsd/default.htm). The per capita nominal GDP estimates compiled by UNSD for all countries and regions since 1970 were selected for use in the present investigation. Since the per capita GDP estimates are available at current prices, they already account for exchange rate changes and inflation adjustments (http://unstats.un.org/unsd/snaama/estimationProcess.asp).

\section{Catalog of Economic Losses for Historical Earthquakes}

Several independent databases covering earthquake-related information exist (for example, the USGS NEIC catalog, NOAA's NGDC Significant Earthquake Database, the Utsu catalog, PAGER-CAT, and EMDAT catalog; see Allen and others (2009b) for a partial summary. Most of these catalogs have different aims, and they do not often focus on economic losses. Proprietary earthquake loss data also exist; for example, Munich Re's catalog, which is available through their NatCat Service (NatCat Service, 2008). This standardized catalog contains more than 27,000 entries covering a wide range of natural disasters compiled over several decades. The Munich Re 
data, specific to earthquakes between 1980 and 2008, were made available for the present investigation through the Global Earthquake Model (GEM) project. There are 2,183 entries compiled during 29 years for 2,083 earthquake events which caused at least 10,000 USD of economic loss. Although separate estimates are provided for insured losses, we used the total direct economic loss figures which are total losses reported for building damage, infrastructure, and other causes (table 2).

Earthquakes that resulted in losses across multiple countries are provided with separate country-specific losses. Loss values (in USD) are due to the direct economic impact from shaking and other earthquake-induced hazards; for example, landslides, mudslides, rock falls, tsunamis, and fires.

Table 2. Munich Re's total direct economic loss data for selected events (Source: NatCatSERVICE, 2008).

\begin{tabular}{|l|l|l|l|l|}
\hline MR Number & Country & $\begin{array}{l}\text { Direct overall } \\
\text { loss (USD } \\
\text { million, original } \\
\text { values) }\end{array}$ & $\begin{array}{l}\text { Insured Loss } \\
\text { (USD million) }\end{array}$ & Deaths (Total) \\
\hline MR199401A043 & $\begin{array}{l}\text { Northridge, CA, } \\
\text { USA }\end{array}$ & 44,000 & 15,300 & 61 \\
\hline MR199501A046 & Kobe, Japan & 100,000 & 3,000 & 6,430 \\
\hline MR199909A017 & Chi Chi, Taiwan & 14,000 & 750 & 2,368 \\
\hline MR200805A004 & Sichuan, China & 85,000 & 300 & 69,227 \\
\hline
\end{tabular}

\section{Economic Exposure}

We now describe how the GDP-based exposure and economic losses are correlated and also discuss the necessity of scaling the total GDP to accommodate economic exposure/wealth of the region. The population exposure at each intensity level and the country-level per capita GDP 
estimates scaled using the exposure correction factor are used to approximate regional economic exposure.

\section{GDP and Economic Loss}

Past researchers have correlated historical earthquake losses with the total GDP of a region (Chan and others, 1998; Chen and others, 2001; Dunbar and others, 2002). GDP represents average annual productivity. Total earthquake loss from any single earthquake is not limited by GDP and it can exceed the GDP of a country. For example, the November 6, 1988 Burma-China earthquake caused loss on the order of 4.6 times the region's GDP (Chan and others, 1998); the Aug 19, 1992 Kyrgyzstan earthquake resulted in damages exceeding 5 times the total GDP of the region (Dunbar and others, 2002); and the 2010 Haiti earthquake losses exceeded the GDP of the country (http://www.businessweek.com/news/2010-03-20/haiti-earthquake-damage-to-cost-7-8-billion-uns-barcena-says.html). Thus, the total earthquake loss can be proportional to GDP, but the proportion appears to be country-specific. Also, the actual economic exposure of assets at risk is larger than GDP and it may be some scalar multiple of GDP. Finally, for earthquake shaking that affects only a portion of the country, we may need to find a way to apportion the total GDP of the country to the part of the country that is affected by the earthquake. This can be partly done by estimating the affected population and its economic exposure at the time of earthquake as described in the subsequent section.

\section{Inventory-based Exposure/Wealth and Economic Loss}

Inventory-based approaches for economic exposure estimation require detailed categorization of various types of assets; such as location, structural and occupancy characteristics, age, asset value, and so forth. While estimating the economic losses from a repeat of a 1906 San Francisco earthquake, Kircher and others (2006) provided an assessment of economic exposure of 
building stock of 19 counties in Northern California. The study underscored the significant challenges associated with economic exposure estimation and its impact on earthquake loss estimations. Using the default exposure available through HAZUS (FEMA, 2006), we find that economic exposure of building stock is on an average 3 times the total GDP of the region in the year 2000 (California's per capita GDP in 2000 was 37,848 USD [http://www.economicscharts.com]). Note that the total economic exposure estimated in Kircher and others' study was limited to building stock (both residential and non-residential) only. The non-building facility exposure - such as industrial infrastructure, road, rail, electricity network, bridges, dams, and other miscellaneous infrastructural facilities - could be several times higher than the total building exposure. To estimate the total direct loss it is necessary to estimate the total economic value of all the exposed assets, such as buildings, infrastructure, and so forth.

Inventory-based exposure estimation approaches are data-dependent and demand detailed analysis, thus they may not be suitable for rapid loss estimation at a global scale. Also, the macroscopic approaches using GDP alone (which is the most commonly recognized indicator of economic activity) are not sufficient. GDP is a measure of economic activity, not of existing investment, which is required for estimating exposure. Since data on investments are not readily available, we devised a method to estimate the investment on economic exposure from the readily available data on GDP.

In a recent study by the World Bank (2006) titled 'Where is the Wealth of Nations?' the authors considered several important factors - including estimates of capital produced, physical capital stock, consumption, investment, natural resources, and other factors - to compute the per capita wealth (in the year 2000) for 119 countries. The wealth estimate per capita is an important and useful indicator of economic well being of a region or country. We use per capita wealth 
information to estimate the exposure correction factor, $\alpha$, for each country by taking the ratio of per capita wealth to per capita GDP in 2000 as shown in Table 3.

Table 3. Estimating exposure correction factor using GDP and wealth data for selected countries.

\begin{tabular}{|l|l|l|l|}
\hline Country & $\begin{array}{l}\text { Per capita GDP in } \\
2000\end{array}$ & $\begin{array}{l}\text { Per capita Wealth in } \\
2000\end{array}$ & $\begin{array}{l}\text { Exposure correction } \\
\text { factor }(\alpha)\end{array}$ \\
\hline Albania & $\$ 1,187$ & $\$ 17,312$ & 14.6 \\
\hline Australia & $\$ 20,844$ & $\$ 371,031$ & 17.8 \\
\hline Chile & $\$ 4,877$ & $\$ 77,726$ & 15.9 \\
\hline Italy & $\$ 19,213$ & $\$ 372,666$ & 19.4 \\
\hline Japan & $\$ 36,837$ & $\$ 493,241$ & 13.4 \\
\hline Nigeria & $\$ 371$ & $\$ 2,639$ & 7.1 \\
\hline $\begin{array}{l}\text { Trinidad and } \\
\text { Tobago }\end{array}$ & $\$ 6,296$ & $\$ 57,549$ & 9.1 \\
\hline Turkey & $\$ 4,011$ & $\$ 47,859$ & 11.9 \\
\hline United States & $\$ 33,924$ & $\$ 512,612$ & 15.11 \\
\hline
\end{tabular}

The exposure correction factor obtained here represents the ratio of per capita wealth to per capita GDP, both obtained for the year 2000. Since the data on per capita wealth by country are unavailable for all other years, we assumed that the exposure correction factor is constant for a given country. It can be argued that such a factor could change every year; however, since we only use $\alpha$ to normalize historical losses, it is less sensitive to change than annual per capita GDP estimates.

Per capita GDP estimates available since the 1970s, population exposure available through EXPO-CAT, and the country-specific exposure correction factor shown in Table 3 are used to approximate the economic exposure at the time of the earthquake as described in the following section. 


\section{Methodology}

Jaiswal and others (2009) proposed an empirical approach to rapidly estimate human fatalities in the immediate aftermath of a large earthquake anywhere in the world. The authors defined the fatality rate as the total number of shaking-related fatalities to the total number of people exposed per level of shaking intensity. The principle of estimating casualties from the total human exposure using fatality rates can be extended to the computation of economic losses using a loss ratio function that replaces human exposure with economic exposure. The economic loss ratio $r$ is defined as the economic loss normalized by the economic exposure as shown below.

$$
\text { Loss Ratio, } r=\frac{\text { Eco. Loss }}{\text { Eco. Exposure }}
$$

Similar to the fatality rate procedure applied in Jaiswal and others (2009), the loss ratio $r$ in the present case is parameterized in terms of shaking intensity $s$ using a two-parameter lognormal cumulative distribution function given as

$$
r(s)=\phi\left[\frac{1}{\beta} \ln \left(\frac{s}{\theta}\right)\right]
$$

where $\varnothing$ is the standard normal cumulative distribution function and parameters $\theta$ and $\beta$ are the mean and standard deviation of natural logarithm of shaking intensity. In other words, these parameters describe the scale and shape of a loss ratio function, respectively. The cumulative lognormal distribution function has various useful properties and is widely used for modeling the structural fragility/damage due to earthquakes (FEMA, 2006). In the present application, the shaking intensity $s$ ranges from 5.0 to 9.0 , where total exposure at MM intensity IX and above is combined at IX. 
Unfortunately, for the last thirty years per capita GDP estimates are unavailable at a resolution higher than the country level. However, assuming that the per capita GDP does not vary significantly from one region to another (unless the area is highly industrial or rural) within a given country, we can estimate the total GDP exposed to each level of shaking. This approach is similar to the work of Dilley and others (2005), in which GDP per unit area and population were used to measure economic exposure at a grid level resolution. We use country-level estimates to apportion the total GDP of the country into the region's GDP under the assumption that per capita GDP estimates are uniform within a country:

$$
G D P_{(\text {region, s) }}=\text { per capita } G D P_{\text {Country }} \times \text { population }_{(\text {region, } s)}
$$

The total economic exposure at a given intensity can be computed using GDP exposed to that intensity multiplied by the exposure correction factor $\alpha$ :

$$
\text { Economic.Exposure }_{s}=\alpha_{\text {region }} \times G D P_{(\text {region, } s)}
$$

Note that the exposure correction factor $\alpha$ is taken for the year 2000 and is constant here. However, if per capita wealth data become available one can easily compute the exposure correction factor $\alpha$ specific to each year.

The total expected economic loss following an earthquake is estimated by summing the product of total economic exposure and loss ratio at each shaking intensity level:

$$
E(\text { Loss })=\sum_{s} r(s) \times \text { Economic Exposure } \text { Ex }_{s}
$$

which can be written as

$$
E(\text { Loss })=\sum_{s} \phi\left[\frac{1}{\beta} \ln \left(\frac{s}{\theta}\right)\right] \times \text { Eco. Exposure }_{s}
$$


The loss ratio function $r$ defined in terms of logarithmic cumulative distribution function of shaking intensity depends upon two unknown parameters, $\theta$ and $\beta$, that needed to be determined for each country or region. If we suppose that $O_{i}$ is the recorded economic loss (in millions of USD taken from the Munich Re catalog) for an earthquake $i$, and there are $N$ earthquakes in that country, then we can search for the parameters of loss ratio function in such a way that the total error $\varepsilon$ between expected loss $E$ (Loss) (also termed as model estimated loss abbreviated as $E_{i}$ and recorded losses $O_{i}$ ) is minimized using the following combined norm proposed by Jaiswal and others (2009):

$$
\varepsilon=\ln \left[\sqrt{\frac{1}{N} \sum_{i=1}^{N}\left[E_{i}-O_{i}\right]^{2}}\right]+\sqrt{\frac{1}{N} \sum_{i=1}^{N}\left[\ln \left(\frac{E_{i}}{O_{i}}\right)\right]^{2}}
$$

The authors concluded that the combined least squares and logarithmic difference norms were most suitable given the typical distributions of losses: a large number of small losses and a few, but important, significant-loss events. This combination optimizes the match at both high and low loss levels.

A standard iterative search algorithm is used to minimize the objective function shown in equation 7. The parameters $\theta$ and $\beta$ obtained using this procedure are country or region-specific as demonstrated in the later part of this report.

In order to assess the total variability of expected loss obtained using equation 1 given the catalog recorded losses for historical earthquakes, we estimate the normalized standard deviation $\zeta$ (Greek alphabet, zeta) of the logarithm of recorded loss given the model-estimated loss:

$$
\zeta=\sqrt{\frac{1}{N-2} \sum_{i=1}^{N}\left[\ln \left(O_{i}\right)-\mu_{\left.\ln O_{i} \mid \ln E_{i}\right]^{2}}\right.}
$$


The expected (or mean) value of actual loss $\mu_{\ln O \ln E}$ given the model-estimated loss can be obtained by performing linear regression $\ln (O)=c+m \ln (E)$ on all earthquakes in that country or region.

\section{Uncertainty in Model Parameters}

In order to estimate the standard errors associated with these parameters, a jackknife technique is employed here. In principle, we determine these parameters by reducing the sample (the number of earthquakes being used to estimate the parameters) of size $N$ by one and then producing new estimates for $\theta$ and $\beta$. If $\theta_{1}, \theta_{2}, \theta_{3}, . ., \theta_{N}$ and $\beta_{1}, \beta_{2}, \beta_{3}, \ldots, \beta_{N}$ represent the estimates of two model parameters obtained by the jackknifing technique through $N$ experiments with effective

sample size of $N-1$, then we can compute the jackknife estimates, namely $\hat{\theta}_{j a c k}$ and $\hat{\beta}_{j a c k}$, for each country (or region) as shown below:

$$
\hat{\theta}_{j a c k}=\frac{1}{N} \sum_{i=1}^{N} \theta_{i}
$$

and

$$
\hat{\beta}_{\text {jack }}=\frac{1}{N} \sum_{i=1}^{N} \beta_{i}
$$

and the associated standard errors are obtained using following equations

$$
\delta_{\theta}=\sqrt{\frac{N-1}{N} \sum_{i=1}^{N}\left(\theta_{i}-\hat{\theta}_{j a c k}\right)^{2}}
$$

and

$$
\delta_{\beta}=\sqrt{\frac{N-1}{N} \sum_{i=1}^{N}\left(\beta_{i}-\hat{\beta}_{j a c k}\right)^{2}}
$$


The standard errors represent a measure of uncertainty in the model parameters $\theta$ and $\beta$.

\section{Estimating Fractiles of an Estimated Loss}

The economic loss obtained using equation 6 represents the mean value of loss for a given earthquake. By studying the model's uncertainty in terms of its predictability for historical earthquakes, we obtain a normalized standard deviation of the logarithm of loss in equation 8 represented by $\zeta$. Assuming that the estimated loss from the model is a lognormal random variable with expected value $\mu_{l n L}$ and a standard deviation of $\zeta$, we can estimate the probability of a certain predefined loss threshold $(\mathrm{a}, \mathrm{b})$ using the following:

$$
P(a<L \leq b)=\phi\left[\frac{\ln b-\mu_{\ln L}}{\zeta}\right]-\phi\left[\frac{\ln a-\mu_{\ln L}}{\zeta}\right]
$$

Here, the expected value of the logarithm of loss is simply taken as the logarithm of the estimated value of loss directly obtained from the model, and the standard deviation represents the estimated value of $\zeta$ for a given country or region.

Note that the estimate of the standard deviation here is strongly dependent upon the number of earthquakes (from the catalog) that are being used to estimate it (equation 8) as well as the normalized measure of deviation of the logarithm of estimated versus recorded losses (across different ranges of losses) for the earthquakes that are being used to create the model. Thus, the true standard deviation of loss may not be accurately represented here, especially for countries where the recorded catalog sample size is either limited or covers only a limited range of losses.

Figure 3 a illustrates for a fictitious case the estimate of cumulative probability of loss given the model's estimate of mean loss $\mu_{\ln L}$ with standard deviation $\zeta_{\ln L}$. The 90-percentile loss can be estimated using the following: 


$$
P\left(L \leq l_{0.9}\right)=\phi\left[\frac{l_{0.9}-\zeta_{\ln L}}{\mu_{\ln L}}\right]
$$

Figure $3 b$ shows the estimate of probability of different loss thresholds (that is, between 1;

$10 ; 100 ; 1,000 ;$ and 10,000) using equation 13 .

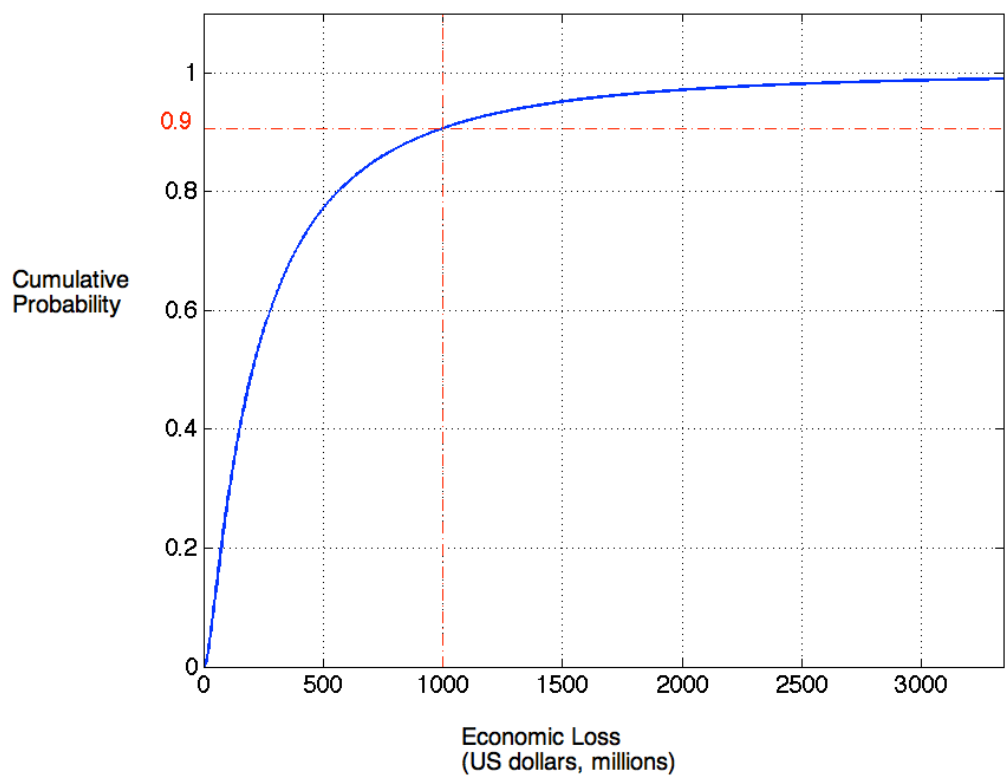

(A)

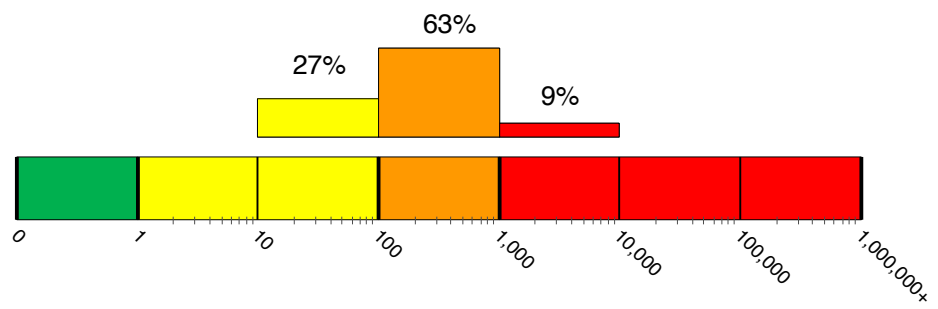

(B)

Figure 3. Probability distribution (for $E(L)=205, \zeta=1.2$ ) diagram showing estimates of probability of occurrence with different threshold levels of losses. (A), Cumulative probability estimates at certain thresholds of loss. (B), Histogram showing probability estimate at different thresholds. 
The likelihood of different loss thresholds is used to depict the range of uncertainty associated with PAGER's rapid loss estimates to facilitate effective decision making (Wald and others 2011) as illustrated in Figure 4.

\begin{tabular}{|ccc|}
\hline Alert level and color & Estimated fatalities & Estimated losses (U.S. \$\$) \\
\hline Red & $1,000+$ & $\$ 1$ billion+ \\
Orange & $100-999$ & $\$ 100$ million $-\$ 1$ billion \\
Yellow & $1-99$ & $\$ 1$ million $-\$ 100$ million \\
Green & 0 & $<\$ 1$ million \\
\hline
\end{tabular}

(A) PAGER alert threshold based on range of estimated fatalities and economic losses.

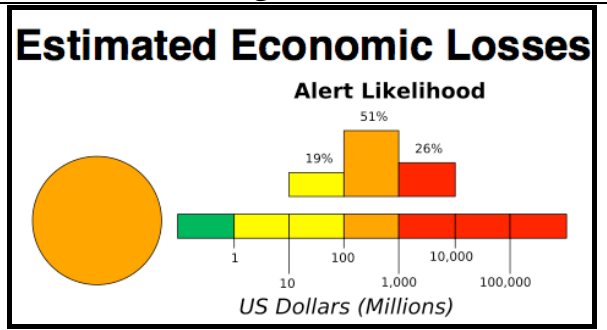

(B) Likelihood of ranges of losses resulting from a fictitious earthquake depicting the range of uncertainty associated with the PAGER loss estimates. Note that the yellow alert threshold is divided into two levels due to logarithmic impact scale.

Figure 4. Illustration of PAGER earthquake impact alert estimates.

In principle, we want to utilize the loss estimates available through the USGS PAGER system in a substantive way through a new earthquake impact alert protocol. The losses are thus measured using an Earthquake Impact Scale (EIS), which provides a meaningful assessment of what most critical users need to know in the aftermath of an earthquake in order to make informed decisions. The logarithm-based loss thresholds shown in Figure 4 for fatality and economic losses represent the measure of green, yellow, orange, and red alert levels. In the context of response activation, the authors note that these alert levels directly correspond to no response, local response, regional response, and national or international levels of response that may have been needed for past earthquakes with such losses. It is possible to estimate the range of losses using 
equation 13 for a given earthquake as discussed previously, and it can also be interpreted in terms of likelihoods of different alert levels for a given earthquake as shown in Figure $4 \mathrm{~b}$. This scheme not only provides useful and actionable information as quickly as possible, but also makes the user aware of the inherent uncertainties associated with rapid estimation of earthquake losses for global earthquakes.

\section{Estimation of an Earthquake Alert Likelihood for Low Intensity Earthquakes}

In the case of low to moderate intensity earthquakes in certain countries, reports often suggest observation of some localized damage (or 'site-damage' as against the regional damage). By definition, shaking intensities $\mathrm{V}$ and below correspond to the shaking levels that did not cause any damage to the built environment. Historically, low shaking intensities (that is, intensity IV or V) have occasionally been assigned to regions or areas in spite of isolated damage-instances that

may have been caused by unique circumstances or the presence of extremely vulnerable/precarious building stock. So if there is a significant population, say 10,000 , exposed at intensity $\mathrm{V}$, there is a finite probability that such exposure may cause some damage or loss. Unfortunately, given that these are rare occurrences, loss catalogues only represent a biased sample of such outliers without the numerous corresponding zero-loss events. Under such circumstances, in order to produce some trace of loss we use mean loss as $\mu=0.5$ and standard deviation $\zeta$ of a country to plot the alert likelihoods. If the total exposure is below 10,000 at intensity $\mathrm{V}$, we use mean loss $\mu=0.5$ and standard deviation 0.3. This indicates an alert likelihood with an estimated 99 percent probability of no fatalities or less than 1 million USD of economic loss. 


\section{Regionalization Scheme for Global Applications}

In order to develop the empirical model, we needed at least four damaging earthquakes that occurred within a country or region during the observation period between 1973 and 1980. However, only a few countries experienced large, damaging earthquakes for which loss values are available during the observation period, so it was necessary to aggregate some countries into regions in order to have enough damaging earthquakes to estimate the parameters of the economic loss ratio function. This is identical to the procedure described in Jaiswal and others (2009) to develop a regional empirical fatality model where data on fatal earthquakes are lacking. A regionalization scheme that was developed based primarily on geography, building inventory, and social-economic similarities is assumed to be a good starting point for development of regional models. The indicators that were used to group countries with similar vulnerability traits are described briefly below.

\section{Human development index}

The human development index (HDI) combines normalized measures of life expectancy, literacy, education, and gross domestic product per capita worldwide. We use HDI to combine countries with comparable socio-economic classes since they can significantly influence the building construction choices, their quality, and maintenance practices. Poorer socio-economic conditions in south Asian countries such as Pakistan, Nepal, China, and India often negatively affect the way people build and maintain their buildings, and hence, a large number of building collapses due to earthquakes is common in these countries (for example, the 2001 Bhuj earthquake in India, the 2004 Kashmir earthquake in Pakistan and India, and the 2008 Wenchuan earthquake in China). However, in well developed countries such as the United States, Japan, or New Zealand, significant improvements made over the years to improve the seismic resilience of their existing 
building stock has helped reduce building collapses, and consequently, the number of casualties (for example, the Baja, California, earthquake in Mexico that occurred along the US-Mexico border region in 2010; the 2005 Miyagi, Japan, earthquake; and the 2010 Canterbury earthquake in New Zealand).

\section{Climate classification}

In order to tap natural resources such as heat and sunlight, architectural elements such as wall thickness, roof height, number of openings, and choice of construction materials are often dependent upon local climate. For instance, in hot climates buildings tend to employ thick outer walls in order to keep the strong heat outside, while in cold areas it is the inner walls that tend to be thick in order to insulate and keep heat in. For countries with a similar human development index we used climate classification as another qualitative factor for grouping them together. Jaiswal and others (2009) describe the regionalization scheme v1.0 and the most recent version of the scheme is available at $h t t p: / / p u b s . u s g s . g o v / o f / 2009 / 1136 /$.

Figure 5 presents the regionalization proposed by this methodology. Each country that has a country-specific vulnerability function has its own color, while grouped countries share a common color. 


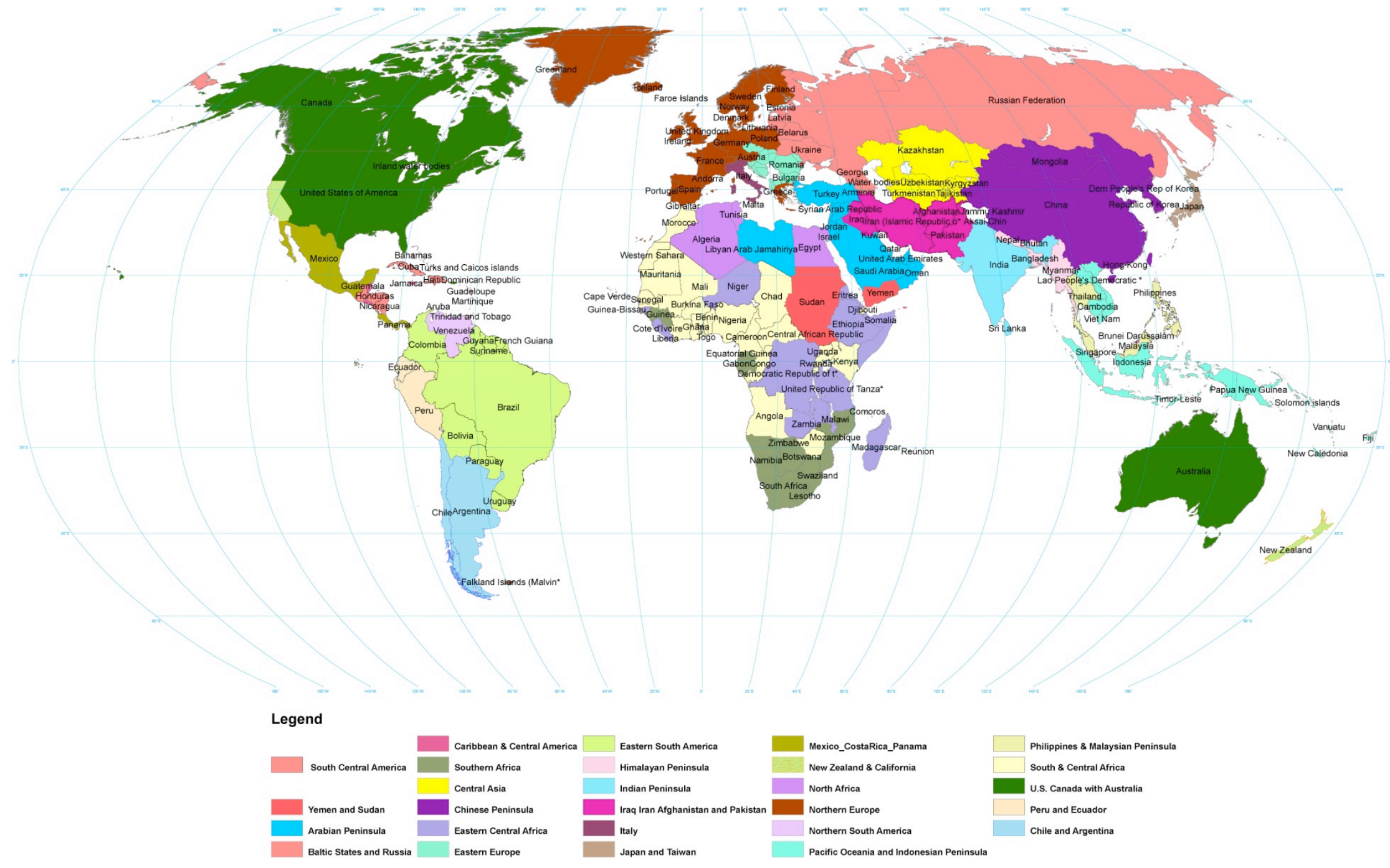

Figure 5. Map showing USGS PAGER Empirical Model Regionalization classification (version 2.0: May 2010). 


\section{Model Development Examples}

We demonstrate the loss ratio function development for individual countries, for example, Japan, Turkey, and Italy by considering historical earthquakes that have contributed to economic losses of 100,000 USD or more. Later, we also demonstrate the development of an empirical model for a region combining earthquakes from several countries. The earthquakespecific economic exposure at each intensity level is calculated for each earthquake by multiplying the total population at a given shaking intensity (available through EXPO-CAT) with per capita GDP for the year in which the earthquake occurred and with the exposure correction factor of that country.

Earthquakes in Japan caused more than one third of the total economic loss worldwide from 1980 to 2008, and the 1995 Kobe earthquake was the most expensive earthquake disaster (with 100 billion USD of direct loss) in this period. A recent study conducted by Risk Management Solutions (RMS) indicates that a repeat of M7.9 Kanto earthquake of 1923 may cause an estimated 80 billion USD of insured property loss (http://www.rms.com/Publications/Japan_EQ.pdf).

We used 79 earthquakes in Japan that caused losses in excess of 100,000 USD from Munich Re's catalog and mapped them with population exposure information from EXPOCAT. Using the new methodology we obtain the parameters $\theta=10.29$ and $\beta=0.1$, with results shown in Figure 6. The gray line in Figure 6a shows a one-to-one match of recorded loss (from EXPO-CAT catalog) and estimated earthquake loss from the model. The two dotted lines represent one order of magnitude in estimated vs. recorded loss. Figure $6 \mathrm{~b}$ shows the loss ratio function plotted using the two parameters and equation 2 . The high standard deviation of $\zeta=$ 1.95 indicates a large spread on estimated losses from the model, as shown in Figure 6a, especially due to earthquakes of moderate size that were reported to cause little damage 
according to the catalog. The estimated economic loss ratio at intensity IX reaches almost 10 percent indicating very high vulnerability in terms of damage and loss for economic exposure (with $\alpha=13.4$ ) exposed at such shaking level in Japan.
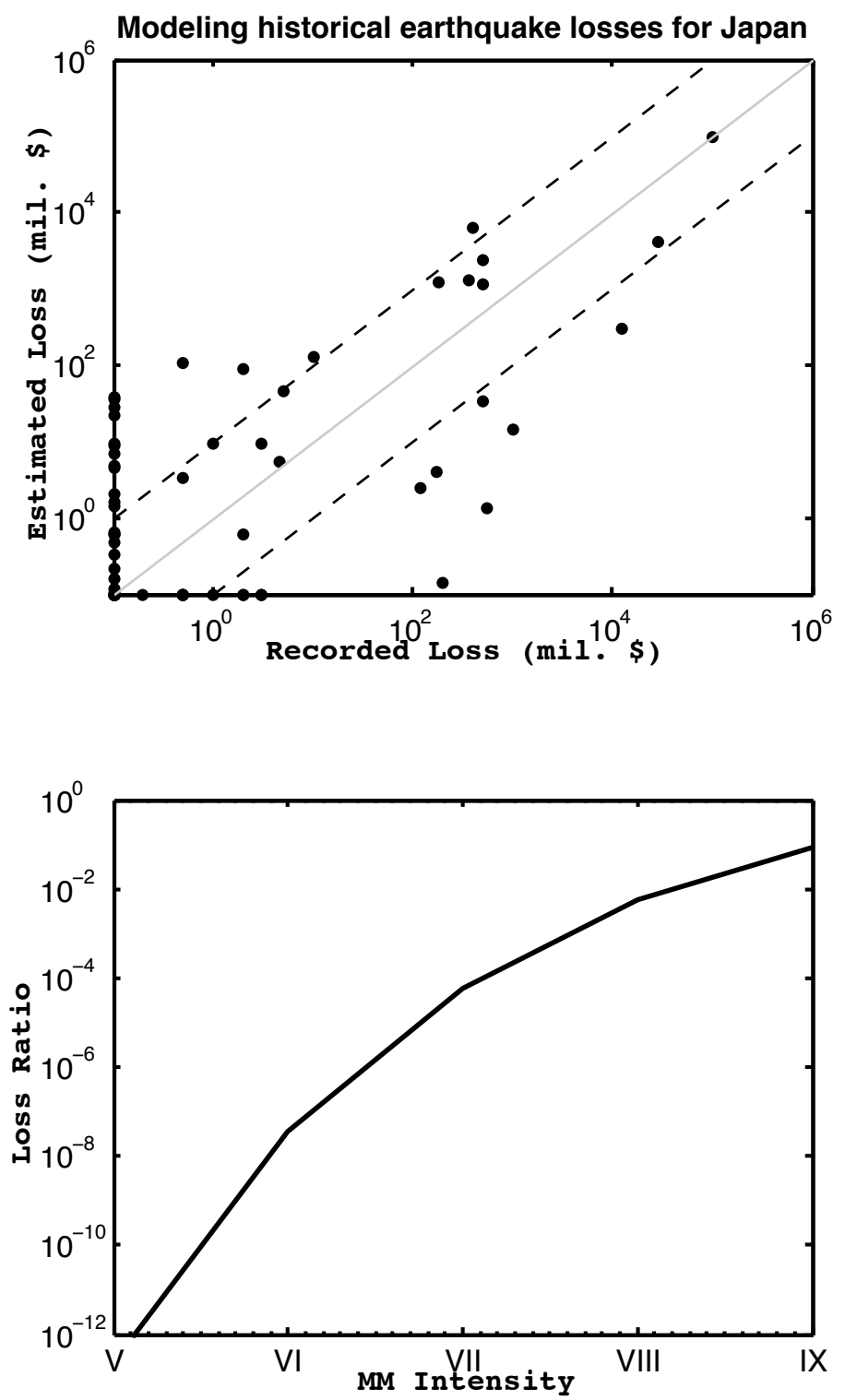

Figure 6. Diagram $(A)$ showing estimated vs. catalog recorded economic losses for historical earthquakes in Japan obtained using $(B)$ economic loss ratio as a function of shaking intensity $(\theta=10.29, \beta=0.1, \zeta=1.95)$.

Figure 7 illustrates recorded versus model-estimated losses for historical earthquakes in Turkey. Each symbol on the top portion of the diagram represents one earthquake for which losses are estimated using the population exposure, GDP, a correction factor, and the loss ratio 
function shown in the bottom portion of the country-specific diagram. We mapped 62 earthquakes in Turkey (1980-2008) for which economic loss estimates were available using EXPO-CAT population exposure data.
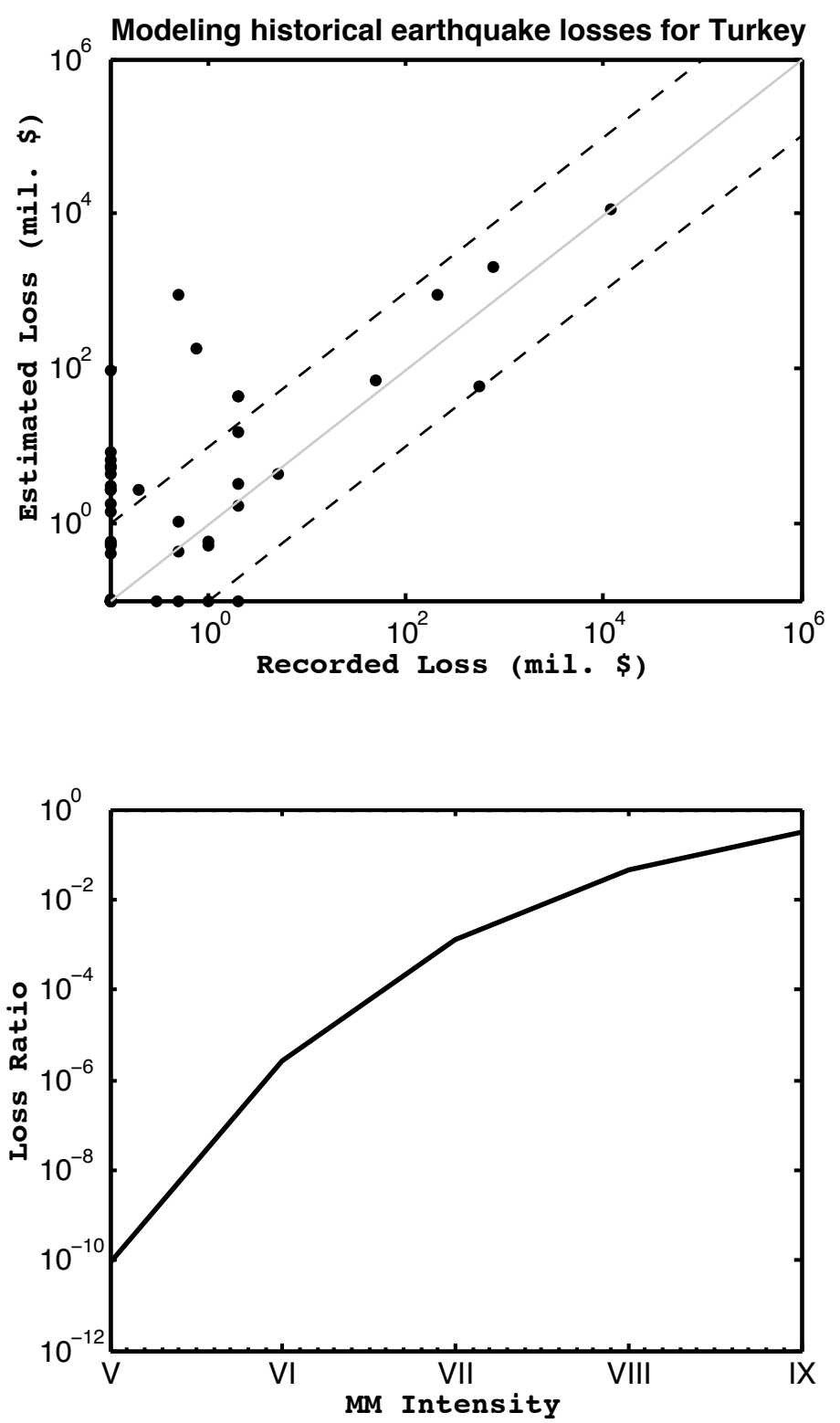

Figure 7. (A) Diagram showing estimated vs. catalog recorded historical earthquake losses for Turkey obtained using $(B)$ economic loss ratio as a function of shaking intensity $(\theta=9.46, \beta=$ $0.1, \zeta=1.3)$.

Among these, the Aug 17, 1999 Izmit earthquake caused 12 billion USD of direct economic loss according to the Munich Re catalog. Using a nonlinear optimization procedure, 
we determined the loss ratio function parameters $\theta$ and $\beta$ that best predict both high and low economic loss events. For the case of Turkey, the estimated parameters are $\theta=9.46$ and $\beta=0.1$, with normalized standard deviation $\zeta=1.3$ as shown in Figure $7 \mathrm{~b}$. Using the economic loss ratio function we estimated 11.46 billion USD of total economic loss for the 1999 Izmit Turkey earthquake (the uppermost symbol $(\bullet)$ on Figure $7 a)$.
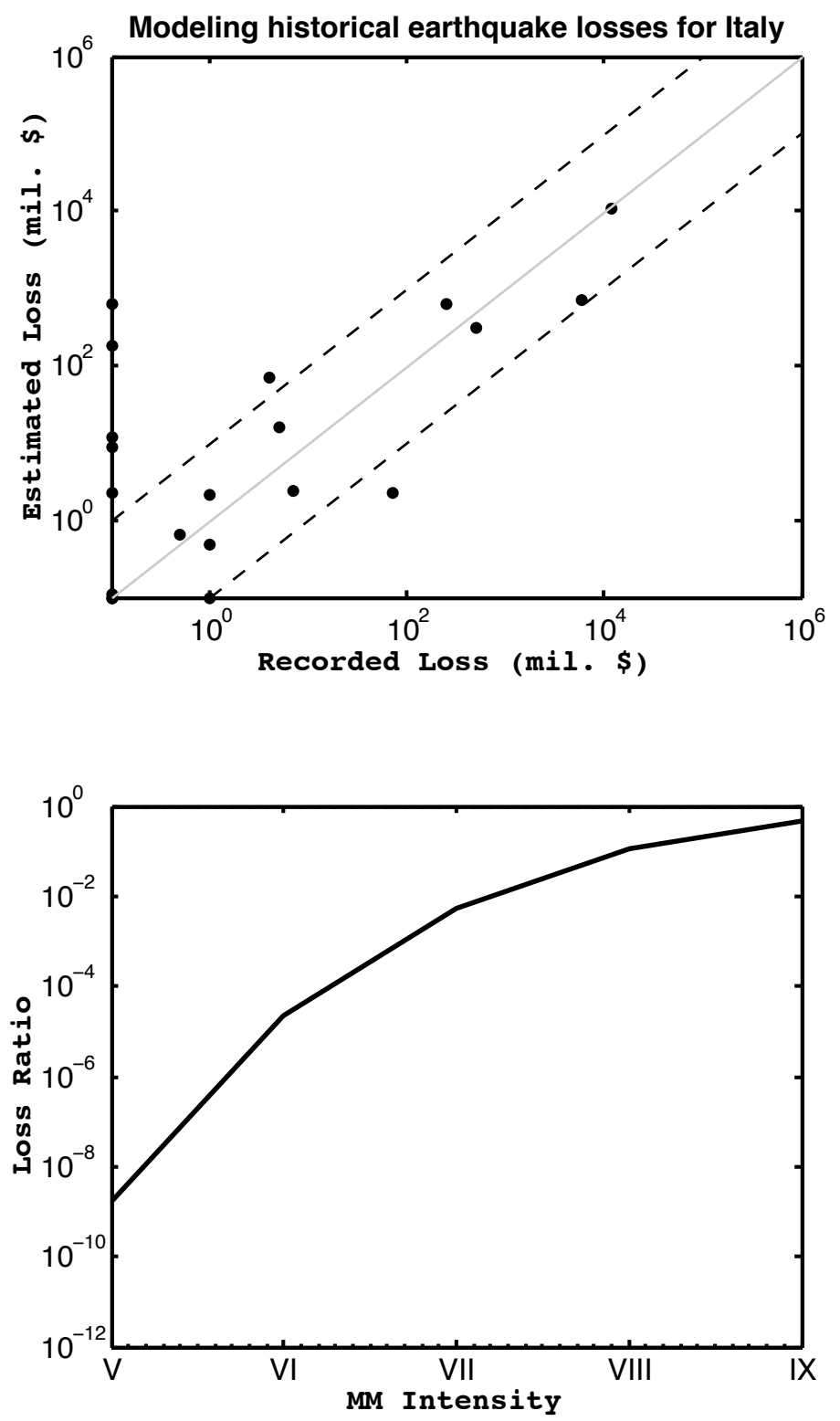

Figure 8. (A) Diagram showing estimated vs. catalog recorded historical earthquake losses for Italy obtained using $(B)$ economic loss ratio as a function of shaking intensity $(\theta=9.03, \beta=0.1$, $\zeta=2.39)$. 
Similarly, using 20 earthquakes that occurred between 1980 and 2007 in Italy, the procedure estimated $\theta=9.03, \beta=0.1$, and $\zeta=2.39$ as shown in Figure 8. One of the most significant earthquakes was the Nov 23, 1980 Irpinia earthquake, which caused 10.9 billion USD of economic loss and 2,914 fatalities. For this event we estimated 11.8 billion USD of economic loss. The relatively higher value of $\zeta$ is due to overestimation of losses for the Feb 14, 1981 earthquake (reported loss of 0.05 million USD) and underestimation of loss for the April 11, 2003 Alessandria earthquake which caused 70 million USD of economic loss.

We now discuss the development of a regional economic model using empirical damage data obtained after grouping the countries with similar vulnerability traits. While deriving the parameters of the loss ratio function, we take country-specific population exposure, GDP, and an exposure correction factor in order to reproduce historical losses for a country. Let us consider the case of Eastern South American countries (Brazil, Bolivia, Colombia, French Guiana, Guyana, Paraguay, Suriname, and Uruguay) where there are only a few damaging earthquakes recorded in the catalog (1980-2008) and thus a country-specific empirical model cannot be derived. Note that each of these countries has a different per capita GDP as well as different exposure correction factors $\alpha$ representing different wealth-to-GDP ratios, as expected. Even though we combine earthquakes from different countries, we estimate losses for an individual earthquake based on the country in which it occurred (and which suffered actual losses). Thus, for an individual earthquake, we use the country and event-specific population exposure, GDP estimate for a given year, and a constant value of the exposure correction factor in order to estimate economic losses.

Nineteen damaging earthquakes reported in Munich Re's catalog for this region have been mapped using EXPO-CAT. Among these, Colombia experienced 13, Brazil experienced 3, 
and Bolivia experienced 2 damaging earthquakes. The most damaging earthquake in the region was recorded on Jan 25, 1999 in Colombia, which caused total direct economic loss of 1,900 million USD. This moderate size (M6.0, Mw 6.2) intra-plate earthquake caused enormous damage and disruption due to ground shaking and other post-shaking hazards such as landslides and fires that affected 28 towns/villages in 5 provinces of the country. It is, however, unclear from Munich Re's catalog the exact value of direct economic loss due to shaking only. EXPOCAT estimates that 27,000 people experienced severe shaking (MM intensity VIII) and almost 400,000 people experienced very strong shaking (MM intensity VII). In 1999, Colombia's per capita GDP estimate was 2,477 USD according to the UN statistical database portal (http://data.un.org/). We used population exposure at the time of the earthquake; per capita GDP in 1999; a constant exposure correction factor of 18.9; and an estimated economic loss ratio function given by $\theta=8.42, \beta=0.1$, with $\zeta=2.19$ to hindcast the economic loss for this earthquake. The empirical model estimated a direct economic loss of 1,000 million USD, which is almost half of the total reported loss for this earthquake (shown in Figure 9 as a part of the regional model for Bolivia). The estimated parameters of the empirical model are based on all nineteen earthquakes in this region and some of these earthquakes have less reported damage than estimated from the model, reflecting the larger spread (standard deviation) shown in Figure 9. Also note that the 1999 earthquake caused widespread damage due to other non-shaking related causes compared to other earthquakes in the region.

For near-future earthquakes in the region, for example in Bolivia, the PAGER system will use earthquake-specific population exposure estimated at the time of earthquake, a per capita GDP (nominal) estimate of 1,722 USD for Bolivia in 2009, and an exposure correction factor of $\alpha=17.97$ to estimate economic loss. This relatively high value of normalized standard deviation $\zeta=2.19$ will be used to illustrate the range of uncertainties associated with estimated economic loss from the empirical model. 
The empirical model parameters derived for selected countries are listed in Table 4 whereas the complete list is in appendix I of this report. With the addition of post-2008 damaging earthquakes from EXPO-CAT, and the availability of a recent GDP dataset, we plan to update appendix I in the near future. The reader should always refer to the most recent version of appendix I for his own applications.
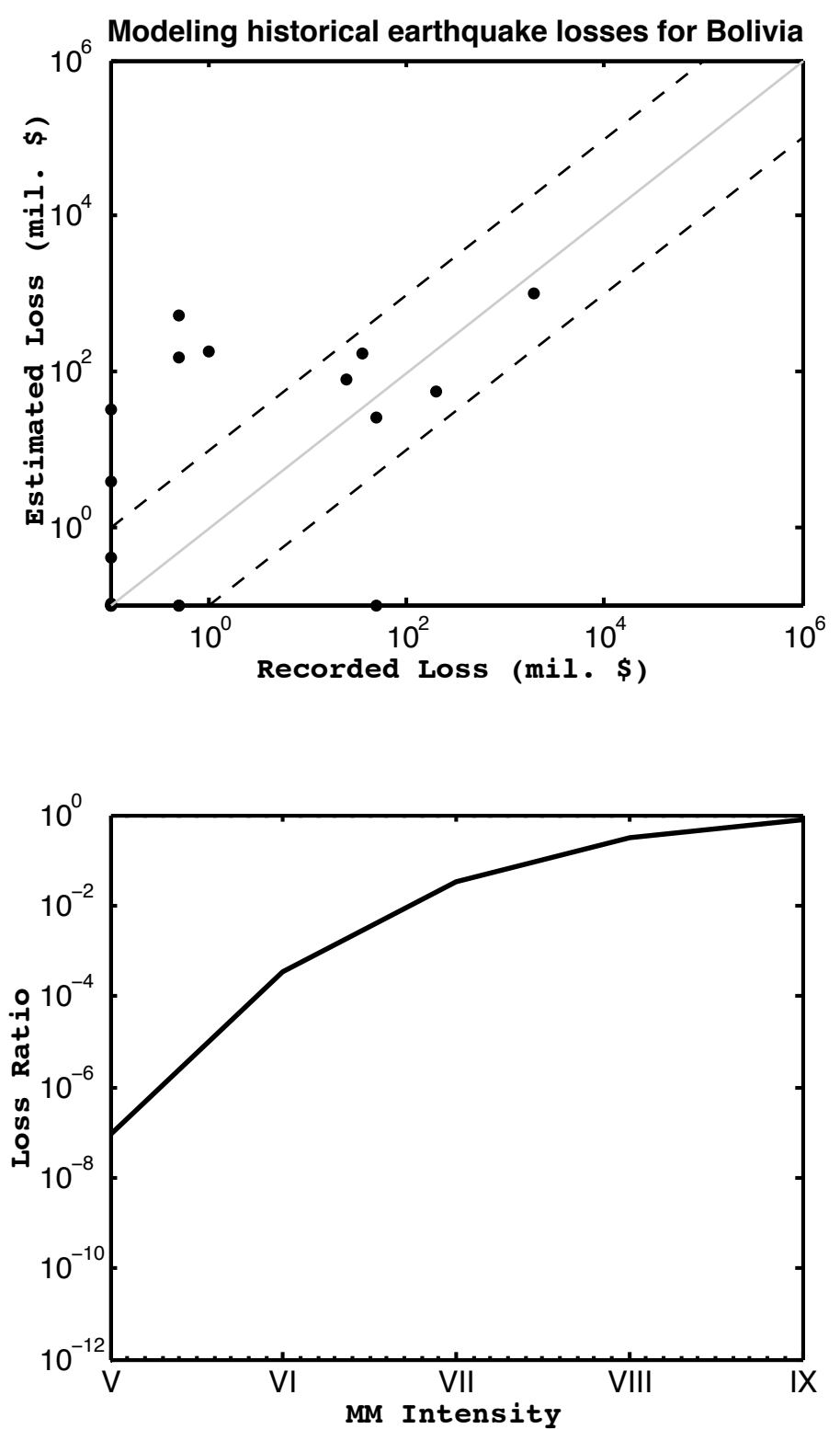

Figure 9. Regional model derived using earthquakes in Eastern South American countries (Brazil, Bolivia, Colombia, French Guiana, Guyana, Paraguay, Suriname, and Uruguay) showing the loss ratio as a function of shaking intensity $(\theta=8.42, \beta=0.1, \zeta=2.19)$. The exposure 
correction factor $\alpha$ as well as per capita GDP estimates is based on statistics available for individual countries.

Table 4. Empirical model parameters for selected countries. Appendix I provides the most recent version of the model parameters derived for all the countries in the globe.

\begin{tabular}{|l|c|c|c|c|c|}
\hline Country & $\theta$ & $\beta$ & $\zeta$ & $\begin{array}{c}\text { Per capita } \\
\text { GDP (2009 } \\
\text { estimates) }\end{array}$ & $\begin{array}{l}\text { Number of } \\
\text { Earthquakes }\end{array}$ \\
\hline Albania & 9.61 & 0.10 & 1.17 & $\$ 4,174$ & 20 \\
\hline Australia & 8.88 & 0.10 & 1.55 & $\$ 48,253$ & 18 \\
\hline Chile & 9.73 & 0.10 & 1.05 & $\$ 10,091$ & 17 \\
\hline Italy & 9.03 & 0.10 & 2.39 & $\$ 38,640$ & 20 \\
\hline Japan & 10.29 & 0.10 & 1.95 & $\$ 38,578$ & 79 \\
\hline Nigeria & 8.64 & 0.10 & 1.84 & $\$ 1450$ & 5 \\
\hline $\begin{array}{l}\text { Trinidad and } \\
\text { Tobago }\end{array}$ & 9.65 & 0.11 & 1.73 & $\$ 18,153$ & 10 \\
\hline Turkey & 9.46 & 0.10 & 1.31 & $\$ 10,031$ & 62 \\
\hline $\begin{array}{l}\text { United States } \\
\text { (without } \\
\text { California) }\end{array}$ & 11.51 & 0.15 & 1.41 & $\$ 45,230$ & 12 \\
\hline California & 9.60 & 0.10 & 2.27 & $\$ 45,230^{*}$ & 38 \\
\hline
\end{tabular}

* per capita GDP for California is assumed to be same as United States.

\section{PAGER Implementation and Loss Estimation for Recent Earthquakes}

Although the PAGER system is developing a three-tiered approach for loss estimation, including empirical, semi-empirical, and fully analytical strategies (Wald and others, 2008), the current operational system for both casualty and economic loss estimates is purely empirical. It was in beta test from the beginning of 2010 until its public release on Sept 29, 2010 (refer to http://earthquake.usgs.gov/earthquakes/pager/). During this time, several large, damaging earthquakes occurred and the loss estimates were only circulated internally to USGS and United States Agency for International Development (USAID) users.

First, we describe the implementation of the economic loss estimation methodology within the PAGER system and then present the results of this methodology for recent 
earthquakes not used in the model development. We used per capita GDP estimates for the year 2009; the LandScan population estimates available for 2008, which were then scaled to the year of the earthquake using annual population growth rates; and an exposure correction factor which was estimated at a benchmark year of 2000 .

For each earthquake, we used the following steps:

(i) Estimate population exposure at different shaking intensity levels,

(ii) Determine the country-specific exposure, and if earthquakes have exposure in multiple countries,

(iii) Estimate economic loss using the appropriate country model and combine the total losses for all countries. Assign the total loss to the country where the epicenter of the earthquake is located and use the $\zeta$ of this country to plot the alert likelihood (range of losses, plus their uncertainties),

(iv) Based on the estimate of total loss, the following criteria are used to assign the earthquake alert:

(a) if estimated loss is less than 1 million USD, assign a green alert for damage. Estimate the likelihoods of other alert levels based on either population exposure criteria as described in the earlier section or using country-specific $\zeta$ and equation 13

(b) if the estimated loss is equal to or greater than 1 million USD but less than 100 million USD, assign yellow alert for damage,

(c) if the estimated loss is 100 million USD or above but less than 1 billion USD, assign orange alert, and finally 
(d) if the estimated loss exceeds the 1 billion USD threshold, assign red alert for damage.

The overall definition of the earthquake alert is based on the higher of the damage and fatality alerts, estimated separately from this model and the Jaiswal and others (2009) fatality model, respectively.

(v) Estimate the overall economic loss in terms of range of percent GDP of the country where it occurred (except in California, where it is estimated based on state's GDP). Construct a one-page impact statement for PAGER using the one sigma range $(\mu \pm \xi)$ of estimated loss measured in terms of percent GDP of the country or region.

In this section, we describe the loss estimates of recent devastating earthquakes produced by the beta pager system; both their initial estimate and how they evolved during the early hours and days of the disasters. One of the deadliest earthquakes in recent history - the magnitude 7.0 Haiti earthquake on Jan 12, 2010-occurred in an area of extremely vulnerable population with minimal resilience to social and economic disruption. The earliest estimate produced by the PAGER system indicated a red alert for fatalities, an orange alert for economic losses, and an overall red alert clearly indicating the need for international intervention and response (fig. 10). Based on the additional constraints of shaking, fault rupture, and intensity reports from the Did You Feel It? (DYFI) system, as well as updated casualty and economic models, we refined our estimates through the operational PAGER system weeks after the earthquake, as shown in Figure 11.

In the case of the magnitude 8.8 Chile earthquake, PAGER (beta version) produced an overall red alert due to the likelihood of potential economic consequences and an orange alert for estimated fatalities, as shown in Figure 12. The loss estimates were revised to incorporate 
finiteness of the rupture area, instrumental recordings, and felt intensities, as shown in Figure 13. Interestingly, the size of the earthquake and the rupture area were enormous compared to the Haiti earthquake; however, the Chilean earthquake resulted in many fewer fatalities compared to the Haiti earthquake. This was mainly due to the existence of relatively modern building-stock built in adherence to Chilean building codes, which have stringent earthquake resistance criteria. The Chile earthquake model, derived using 17 historical USD earthquakes $(\theta=9.73, \beta=0.1, \zeta=1.05)$, estimated economic losses in the range of tens of billions of USD. The earthquake caused widespread damage to buildings and other infrastructure facilities, and it took months to determine the actual consequences. According to the Office of the Coordination of Human Affairs (OCHA), the earthquake and tsunami destroyed more than 81,000 houses and severely damaged an additional 109,000 houses. While the overall economic impact of this earthquake is still undetermined, in April of 2010 OCHA estimated about 30 billion USD in damage and economic loss to the Chilean economy (http://www.usaid.gov/our_work/humanitarian_assistance/disaster_assistance/countries/chile/t emplatelfs_sr/FY2010/chile_eq_fs18_04-22-2010.pdf).

Similarly, within minutes of the 2010 Darfield earthquake in New Zealand, PAGER estimated a red alert for economic losses and a yellow alert for fatalities, indicating overall a low casualty but highly expensive earthquake (fig. 14). The estimated losses were further refined using additional data constraints, such as revised location of the earthquake and revised shaking intensity estimates due to fault rupture extent modeling after the earthquake, which indicated a green alert for fatalities and a red alert for economic losses (fig. 15). The economic loss estimates from the model were in the range of several billion USD, which were reasonable first-order estimates given the 3 billion USD values quoted by the New Zealand Earthquake Commission (EQC). 
Origin Time: Tue 2010-01-12 21:53:09 UTC (16:53:09 local)

Location: $18.45^{\circ} \mathrm{N} 72.45^{\circ} \mathrm{W}$ Depth: $10 \mathrm{~km}$

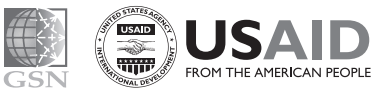

PAGER beta Version

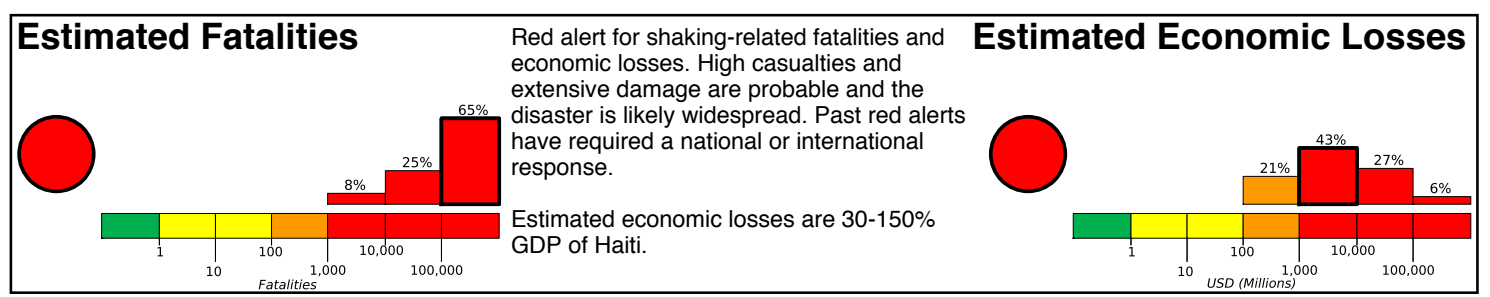

\section{Estimated Population Exposed to Earthquake Shaking}

\begin{tabular}{|c|c|c|c|c|c|c|c|c|c|c|}
\hline \multicolumn{2}{|c|}{$\begin{array}{l}\text { ESTIMATED POPULATION } \\
\text { EXPOSURE }(k=x 1000)\end{array}$} & $--^{*}$ & $--^{*}$ & $7,614 \mathrm{k}^{*}$ & $6,367 \mathrm{k}$ & $1,179 \mathrm{k}$ & $426 \mathrm{k}$ & $1,120 \mathrm{k}$ & $1,824 \mathrm{k}$ & $3 k$ \\
\hline \multicolumn{2}{|c|}{$\begin{array}{l}\text { ESTIMATED MODIFIED } \\
\text { MERCALLI INTENSITY } \\
\end{array}$} & I & ||-||| & IV & V & VI & VII & VIII & IX & $X+$ \\
\hline \multicolumn{2}{|c|}{ PERCEIVED SHAKING } & Not felt & Weak & Light & Moderate & Strong & Very Strong & Severe & Violent & Extreme \\
\hline \multirow{2}{*}{$\begin{array}{l}\text { POTENTIAL } \\
\text { DAMAGE }\end{array}$} & $\begin{array}{c}\text { Resistant } \\
\text { Structures }\end{array}$ & none & none & none & V. Light & Light & Moderate & Moderate/Heavy & Heavy & V. Heavy \\
\hline & $\begin{array}{l}\text { Vulnerable } \\
\text { Structures }\end{array}$ & none & none & none & Light & Moderate & Moderate/Heavy & Heavy & V. Heavy & V. Heavy \\
\hline
\end{tabular}

`Estimated exposure only includes population within the map area.

Population Exposure

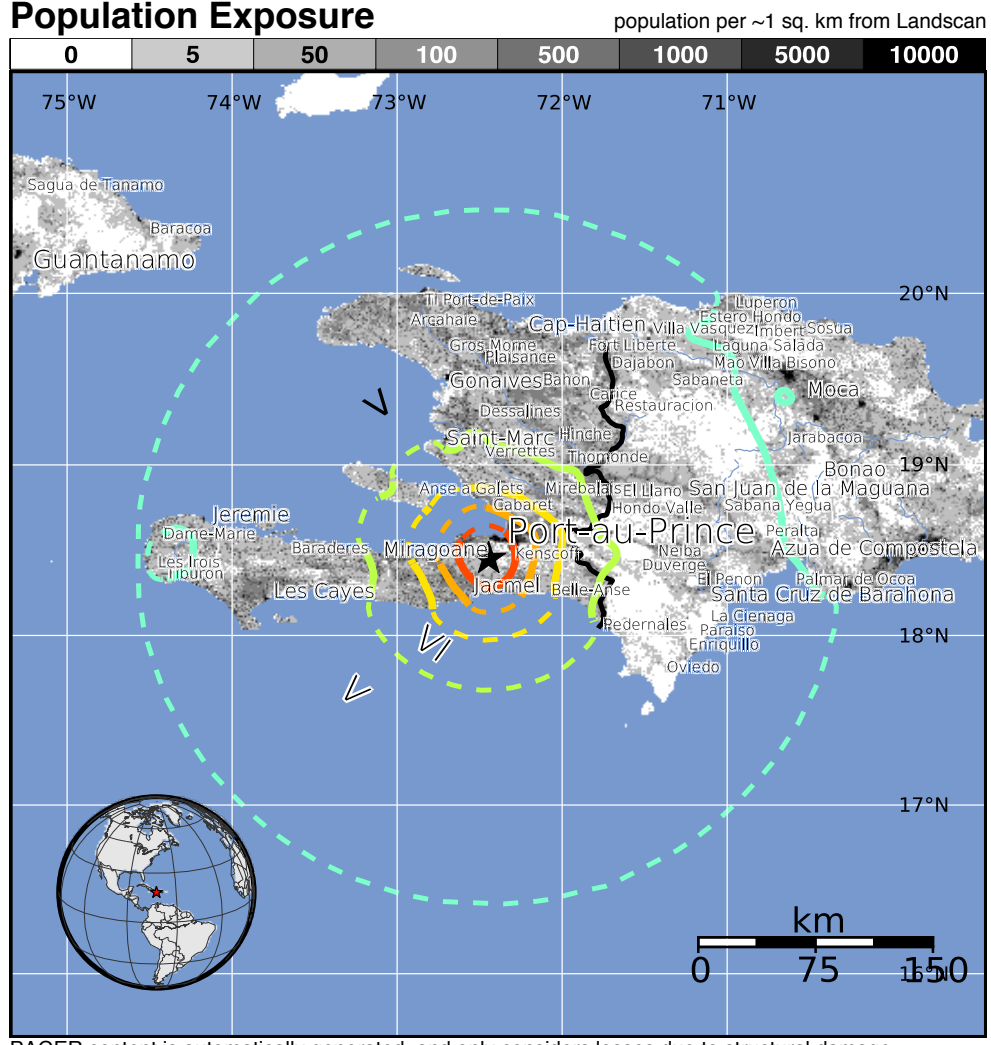

PAGER content is automatically generated, and only considers losses due to structural damage Limitations of input data, shaking estimates, and loss models may add uncertainty. http://earthquake.usgs.gov/pager
Overall, the population in this region resides in structures that are highly vulnerable to earthquake shaking, though some resistant structures exist. The predominant vulnerable building types are concrete/cinder block masonry and mud wall construction.

Historical Earthquakes (with MMI levels):

\begin{tabular}{|lccc|r|}
\hline $\begin{array}{l}\text { Date } \\
\text { (UTC) }\end{array}$ & \multicolumn{2}{c}{$\begin{array}{l}\text { Dist. Mag. } \\
(\mathbf{k m})\end{array}$} & $\begin{array}{c}\text { Max } \\
\text { MMI(\#) }\end{array}$ & $\begin{array}{r}\text { Shaking } \\
\text { Deaths }\end{array}$ \\
\hline $1994-07-12$ & 216 & 5.6 & VIII(6k) & 0 \\
$2003-09-22$ & 235 & 6.4 & IX(131k) & 1 \\
$1984-06-24$ & 329 & 6.7 & VII(320k) & 5 \\
\hline
\end{tabular}

Recent earthquakes in this area have caused secondary hazards such as landslides that might have contributed to losses.

\section{Selected City Exposure}

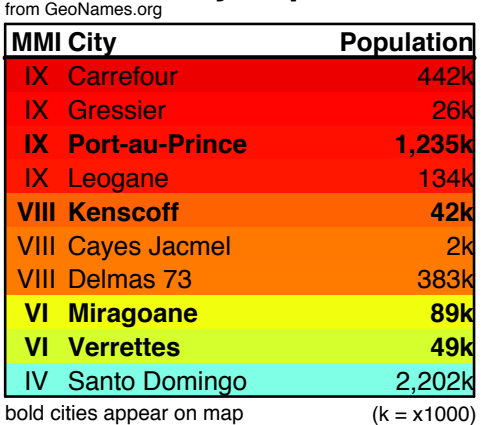

Event ID: us2010rja6

Figure 10. Loss estimates produced by PAGER system (beta version) for the 2010 Haiti earthquake. 


\section{₹USGS}

Earthquake Shaking

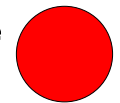

Red

M 7.0, HAITI REGION

Alert

Origin Time: Tue 2010-01-12 21:53:10 UTC (16:53:10 local)

Location: $18.45^{\circ} \mathrm{N} 72.57^{\circ} \mathrm{W}$ Depth: $13 \mathrm{~km}$

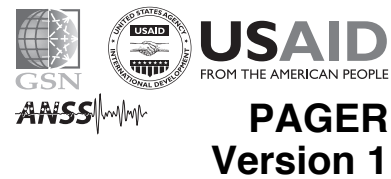

Created: 36 weeks, 2 days after earthquake

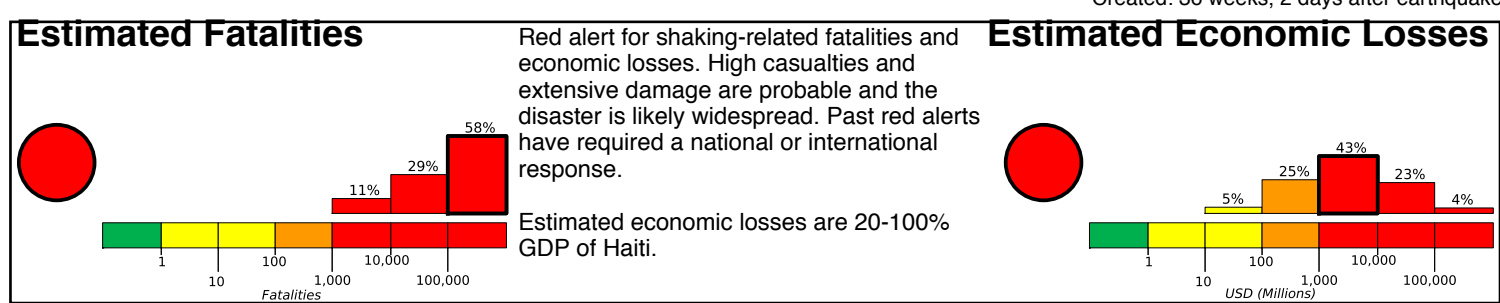

Estimated Population Exposed to Earthquake Shaking

\begin{tabular}{|c|c|c|c|c|c|c|c|c|c|c|}
\hline \multicolumn{2}{|c|}{$\begin{array}{l}\text { ESTIMATED POPULATION } \\
\text { EXPOSURE }(\mathrm{k}=\mathrm{x} 1000)\end{array}$} & $--^{*}$ & $50 k^{*}$ & $7,468 \mathrm{k}^{*}$ & $6,361 \mathrm{k}$ & $926 \mathrm{k}$ & $598 \mathrm{k}$ & $2,030 \mathrm{k}$ & $908 \mathrm{k}$ & $118 \mathrm{k}$ \\
\hline \multicolumn{2}{|c|}{$\begin{array}{l}\text { ESTIMATED MODIFIED } \\
\text { MERCALLI INTENSITY }\end{array}$} & I & |I-III & IV & $\mathbf{V}$ & VI & VII & VIII & IX & $\mathrm{X}+$ \\
\hline \multicolumn{2}{|c|}{ PERCEIVED SHAKING } & Not felt & Weak & Light & Moderate & Strong & Very Strong & Severe & Violent & Extreme \\
\hline \multirow{2}{*}{$\begin{array}{l}\text { POTENTIAL } \\
\text { DAMAGE }\end{array}$} & $\begin{array}{l}\text { Resistant } \\
\text { Structures }\end{array}$ & none & none & none & V. Light & Light & ate & Heavy & Heavy & V. Heavy \\
\hline & $\begin{array}{l}\text { Vulnerable } \\
\text { Structures }\end{array}$ & none & none & none & Light & Moderate & Moderate/Heavy & Heavy & V. Heavy & V. Heavy \\
\hline
\end{tabular}

\section{Population Exposure}

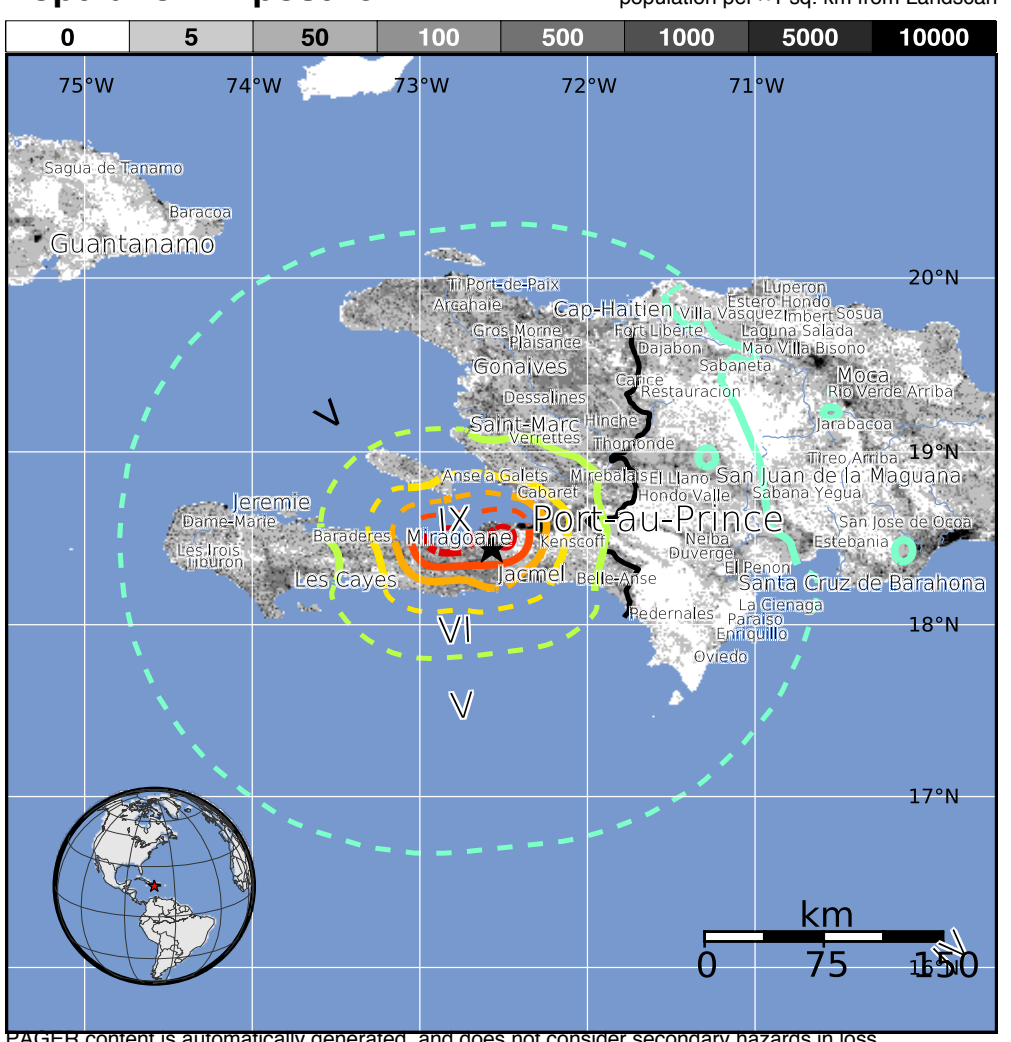

http://earthquake.usgs.gov/pager
Structures:

Overall, the population in this region resides in structures that are highly vulnerable to earthquake shaking, though some resistant structures exist. The predominant vulnerable building types are concrete/cinder block masonry and mud wall construction.

Historical Earthquakes (with MMI levels):

\begin{tabular}{|c|c|c|c|c|}
\hline Date & $\begin{array}{l}\text { Dist. } \\
\text { (km) }\end{array}$ & Mag. & $\begin{array}{c}\text { Max } \\
\text { MMI(\#) }\end{array}$ & $\begin{array}{r}\text { Shaking } \\
\text { Deaths }\end{array}$ \\
\hline $2003-09-22$ & 246 & 6.4 & TX(132k) & \\
\hline 1984-06-24 & 355 & 5.2 & $V(440 k)$ & \\
\hline $1984-06-24$ & 342 & 6.7 & VII(326k) & \\
\hline
\end{tabular}
secondary hazards such as landslides that might have contributed to losses.

\section{Selected City Exposure}

from GeoNames.org

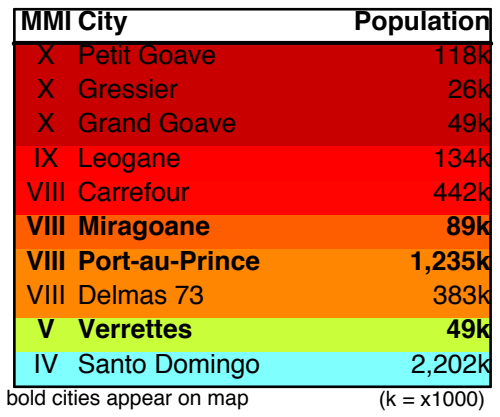

Event ID: us2010rja6

Figure 11. Loss estimates produced by operational PAGER system weeks after the 2010 Haiti earthquake using revised shaking hazard estimates with finite fault model. 
M 8.3, OFFSHORE MAULE, CHILE

Origin Time: Sat 2010-02-27 06:34:17 UTC (02:34:17 local)

Location: $35.83^{\circ} \mathrm{S} 72.67^{\circ} \mathrm{W}$ Depth: $59 \mathrm{~km}$
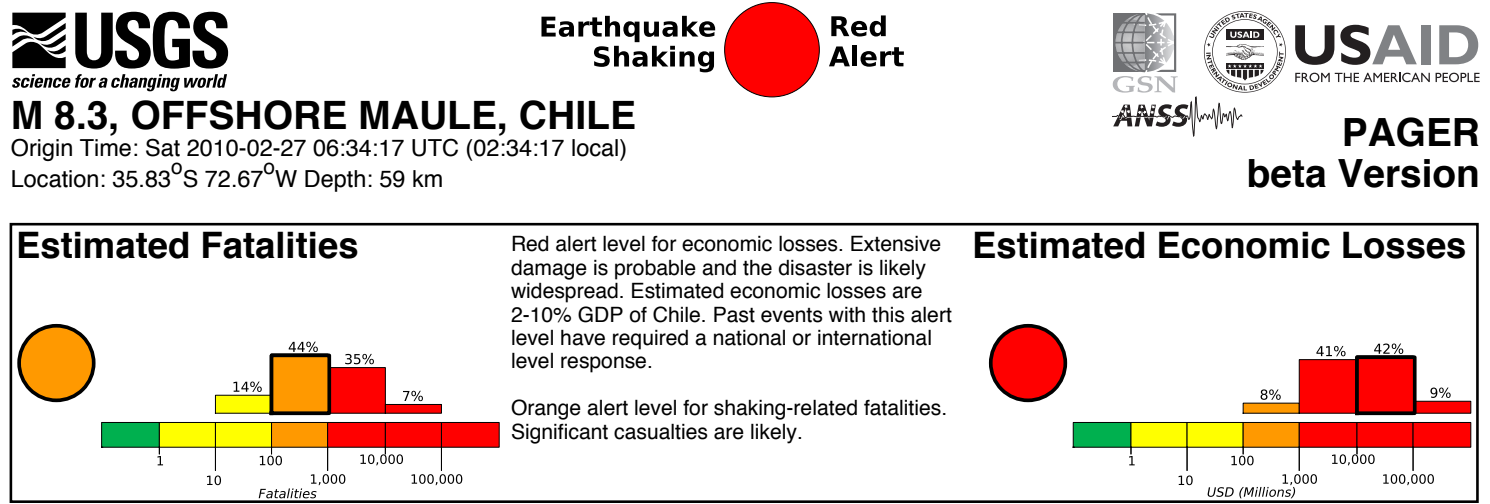

\section{Estimated Population Exposed to Earthquake Shaking}

\begin{tabular}{|c|c|c|c|c|c|c|c|c|c|c|}
\hline \multicolumn{2}{|c|}{$\begin{array}{l}\text { ESTIMATED POPULATION } \\
\text { EXPOSURE }(k=x 1000)\end{array}$} & $--^{*}$ & $--^{*}$ & $--^{*}$ & $56 k^{*}$ & $3,549 \mathrm{k}^{*}$ & $1,345 k$ & $2,538 \mathrm{k}$ & $11 \mathrm{k}$ & 0 \\
\hline \multicolumn{2}{|c|}{$\begin{array}{l}\text { ESTIMATED MODIFIED } \\
\text { MERCALLI INTENSITY }\end{array}$} & I & II-III & IV & V & VI & VII & VIII & IX & $X+$ \\
\hline \multicolumn{2}{|c|}{ PERCEIVED SHAKING } & Not felt & Weak & Light & Moderate & Strong & Very Strong & Severe & Violent & Extreme \\
\hline \multirow{2}{*}{$\begin{array}{l}\text { POTENTIAL } \\
\text { DAMAGE }\end{array}$} & $\begin{array}{l}\text { Resistant } \\
\text { Structures }\end{array}$ & none & none & none & V. Light & Light & Moderate & Moderate/Heavy & Heavy & V. Heavy \\
\hline & $\begin{array}{l}\text { Vulnerable } \\
\text { Structures }\end{array}$ & none & none & none & Light & Moderate & Moderate/Heavy & Heavy & V. Heavy & V. Heavy \\
\hline
\end{tabular}

*Estimated exposure only includes population within the map area.

Population Exposure

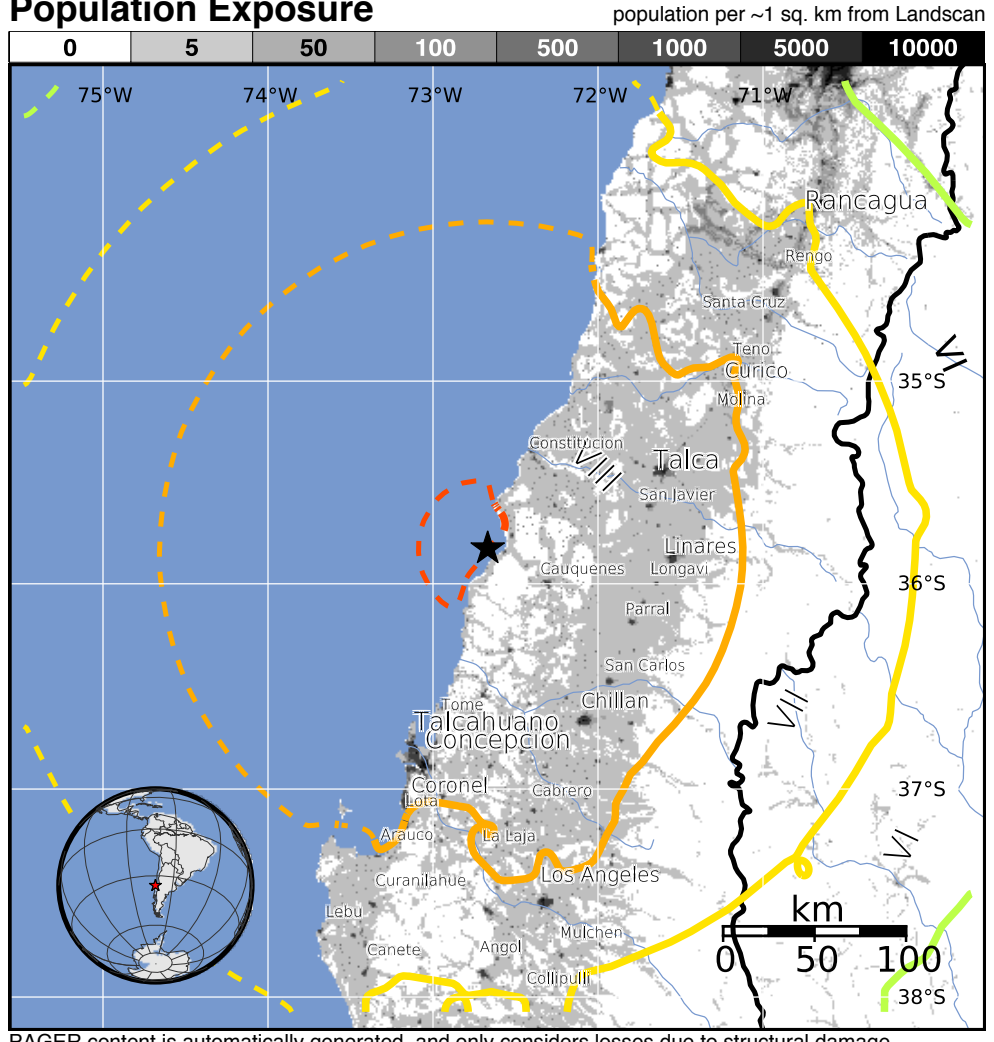

PAGER content is automatically generated, and only considers losses due to structural damage. Pimitations of input data, shaking estimates, and loss models may add uncertainty. http://earthquake.usgs.gov/pager

\section{Structures:}

Overall, the population in this region resides in structures that are resistant to earthquake shaking, though some vulnerable structures exist. The predominant vulnerable building types are low-rise reinforced/confined masonry and adobe block construction

Historical Earthquakes (with MMI levels):

\begin{tabular}{|lcccr|}
\hline $\begin{array}{l}\text { Date } \\
\text { (UTC) }\end{array}$ & \multicolumn{2}{c}{$\begin{array}{l}\text { Dist. Mag. } \\
(\mathbf{k m})\end{array}$} & $\begin{array}{c}\text { Max } \\
\text { MMI(\#) }\end{array}$ & $\begin{array}{r}\text { Shaking } \\
\text { Deaths }\end{array}$ \\
\hline $1974-08-18$ & 298 & 7.1 & $\mathrm{IX}(9 \mathrm{k})$ & 0 \\
$1985-03-03$ & 359 & 7.0 & $\mathrm{IX}(185 \mathrm{k})$ & 0 \\
$1985-03-03$ & 311 & 7.9 & $\mathrm{VII}(5,449 \mathrm{k})$ & 177 \\
\hline
\end{tabular}

Recent earthquakes in this area have caused secondary hazards such as tsunamis

landslides, and liquefaction that might have contributed to losses.

\section{Selected City Exposure}

\begin{tabular}{|lr|}
\hline MMI City & Population \\
\hline IX Cauquenes & $31 \mathrm{k}$ \\
VIII Constitucion & $38 \mathrm{k}$ \\
VIII Parral & $27 \mathrm{k}$ \\
VIII San Javier & $22 \mathrm{k}$ \\
VIII San Carlos & $32 \mathrm{k}$ \\
VIII Longavi & $6 \mathrm{k}$ \\
VIII Talca & $197 \mathrm{k}$ \\
VIII Concepcion & $\mathbf{2 1 5 k}$ \\
VII Rancagua & $\mathbf{2 1 3 k}$ \\
VI vina causino & $510 \mathrm{k}$ \\
VI Santiago & $4,837 \mathrm{k}$ \\
\hline bold cities appear on map & $(\mathrm{k}=\mathrm{x} 1000)$
\end{tabular}

Event ID: us2010tfan

Figure 12. Loss estimates produced by PAGER system (beta version) for the 2010 Chile earthquake. 


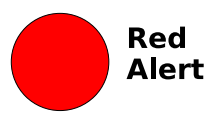

Alert

Origin Time: Sat 2010-02-27 06:34:14 UTC (02:34:14 local)

Location: $35.91^{\circ} \mathrm{S} 72.73^{\circ} \mathrm{W}$ Depth: $35 \mathrm{~km}$

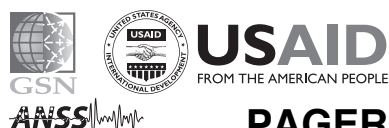

ARSS humply

PAGER

Version 1

Created: 29 weeks, 6 days after earthquake

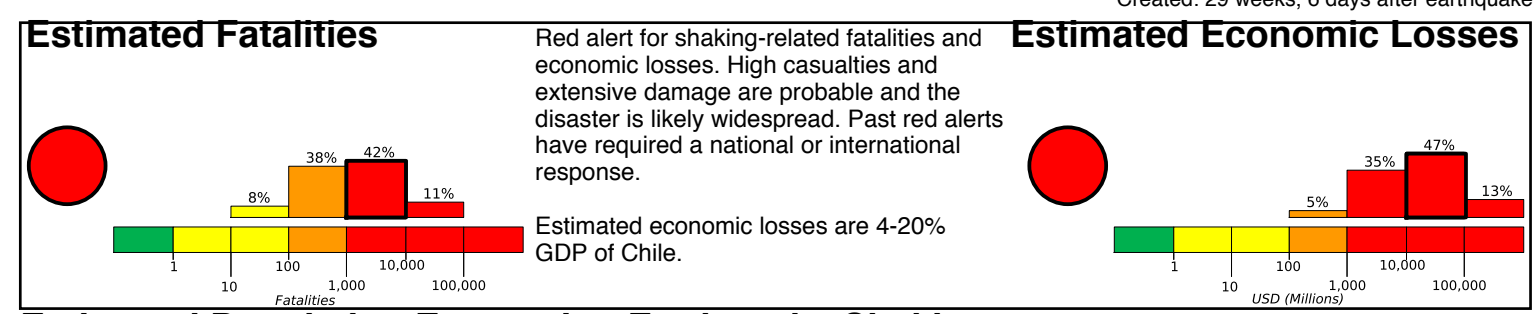

Estimated Population Exposed to Earthquake Shaking

\begin{tabular}{|c|c|c|c|c|c|c|c|c|c|c|}
\hline \multicolumn{2}{|c|}{$\begin{array}{l}\text { ESTIMATED POPULATION } \\
\text { EXPOSURE }(k=x 1000)\end{array}$} & $--^{\star}$ & $202^{*}$ & $1,120 \mathrm{k}^{*}$ & $2,842 \mathrm{k}^{*}$ & $981 k^{*}$ & $9,347 \mathrm{k}$ & $3,649 \mathrm{k}$ & 0 & 0 \\
\hline \multicolumn{2}{|c|}{$\begin{array}{l}\text { ESTIMATED MODIFIED } \\
\text { MERCALLI INTENSITY }\end{array}$} & I & ||-||| & IV & V & VI & VII & VIII & IX & $X+$ \\
\hline \multicolumn{2}{|c|}{ PERCEIVED SHAKING } & Not felt & Weak & Light & Moderate & Strong & Very Strong & Severe & Violent & Extreme \\
\hline \multirow{2}{*}{$\begin{array}{l}\text { POTENTIAL } \\
\text { DAMAGE }\end{array}$} & $\begin{array}{l}\text { Resistant } \\
\text { Structures }\end{array}$ & none & none & none & V. Light & Light & Moderate & Moderate/Heavy & Heavy & V. Heavy \\
\hline & $\begin{array}{l}\text { Vulnerable } \\
\text { Structures }\end{array}$ & none & none & none & Light & Moderate & Moderate/Heavy & Heavy & V. Heavy & V. Heavy \\
\hline
\end{tabular}

Population Exposure

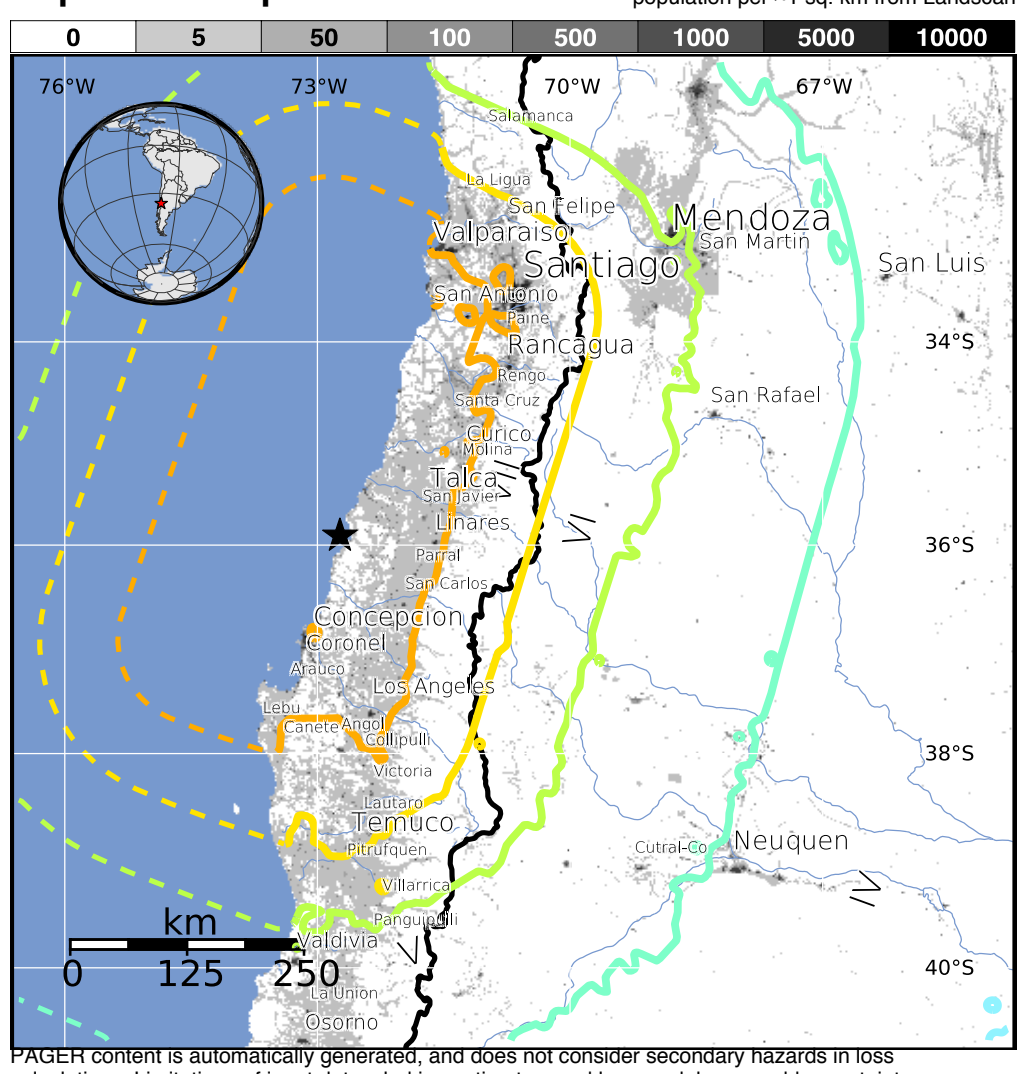

calculations. Limitations of input data, shaking estimates, and loss models may add uncertainty. http://earthquake.usgs.gov/pager
Overall, the population in this region resides in structures that are resistant to earthquake shaking, though some vulnerable structures exist. The predominant vulnerable building types are adobe block with concrete bond beam and unreinforced brick with concrete floor construction.

Historical Earthquakes (with MMI levels):

\begin{tabular}{|c|c|c|c|c|}
\hline Date & $\begin{array}{l}\text { Dist. } \\
\text { (km) }\end{array}$ & Mag. & $\begin{array}{c}\text { Max } \\
\text { MMI(\#) }\end{array}$ & $\begin{array}{r}\text { Shaking } \\
\text { Deaths }\end{array}$ \\
\hline $1985-03-03$ & 315 & 7.9 & VIII(301k) & 0 \\
\hline 1985-03-03 & 359 & 7.0 & $\mathrm{IX}(174 \mathrm{k})$ & 0 \\
\hline $1985-03-03$ & 320 & 7.9 & VII(5,433k) & 177 \\
\hline
\end{tabular}

\section{Selected City Exposure}

from GeoNames.org

\begin{tabular}{|lr|}
\hline MIMI City & Population \\
\hline VIII Arauco & $25 \mathrm{k}$ \\
VIII Coronel & $93 \mathrm{k}$ \\
VII Yumbel & $11 \mathrm{k}$ \\
VII Curanilahue & $31 \mathrm{k}$ \\
VII Cauquenes & $31 \mathrm{k}$ \\
VII Nacimiento & $21 \mathrm{k}$ \\
VII Valparaiso & $282 \mathrm{k}$ \\
VII Santiago & $\mathbf{4 3 3 7 k}$ \\
IV Mendoza & $\mathbf{8 7 7 k}$ \\
IV San Juan & $447 \mathrm{k}$ \\
IV Neuquen & $\mathbf{2 4 2 k}$ \\
bold cities appear on map & $(\mathrm{k}=x 1000)$
\end{tabular}

Event ID: us2010tfan

Figure 13. Loss estimates produced by operational PAGER system weeks after the 2010 Chile earthquake using revised shaking hazard estimates with finite fault model. 


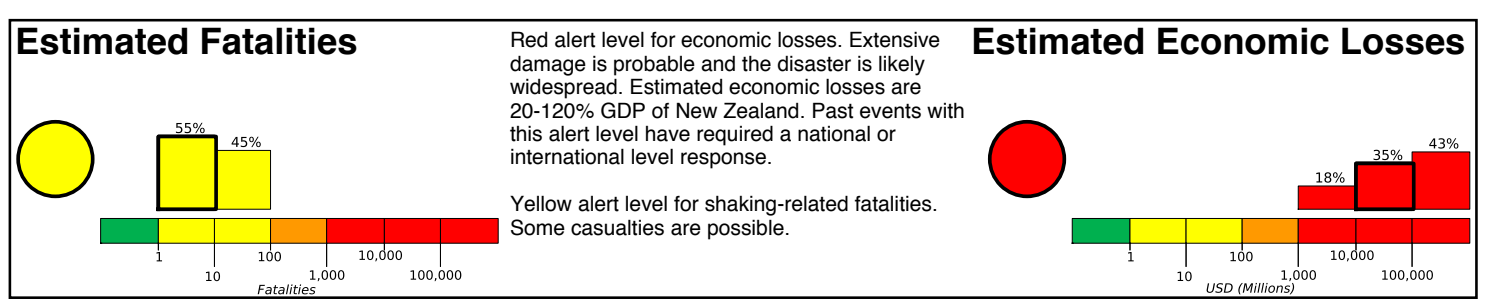

\section{Estimated Population Exposed to Earthquake Shaking}

\begin{tabular}{|c|c|c|c|c|c|c|c|c|c|c|}
\hline \multicolumn{2}{|c|}{$\begin{array}{l}\text { ESTIMATED POPULATION } \\
\text { EXPOSURE }(k=x 1000)\end{array}$} & $--^{*}$ & $919^{*}$ & $177 k^{*}$ & $216 \mathrm{k}$ & $32 k$ & $25 \mathrm{k}$ & $211 \mathrm{k}$ & $191 k$ & $22 k$ \\
\hline \multicolumn{2}{|c|}{$\begin{array}{l}\text { ESTIMATED MODIFIED } \\
\text { MERCALLI INTENSITY }\end{array}$} & I & ||-||| & IV & V & VI & VII & VIII & IX & $X+$ \\
\hline \multicolumn{2}{|c|}{ PERCEIVED SHAKING } & Not felt & Weak & Light & Moderate & Strong & Very Strong & Severe & Violent & Extreme \\
\hline \multirow{2}{*}{$\begin{array}{l}\text { POTENTIAL } \\
\text { DAMAGE }\end{array}$} & $\begin{array}{l}\text { Resistant } \\
\text { Structures }\end{array}$ & none & none & none & V. Light & Light & Moderate & Moderate/Heavy & Heavy & V. Heavy \\
\hline & $\begin{array}{l}\text { Vulnerable } \\
\text { Structures }\end{array}$ & none & none & none & Light & Moderate & Moderate/Heavy & Heavy & V. Heavy & V. Heavy \\
\hline
\end{tabular}

*Estimated exposure only includes population within the map area.

Population Exposure

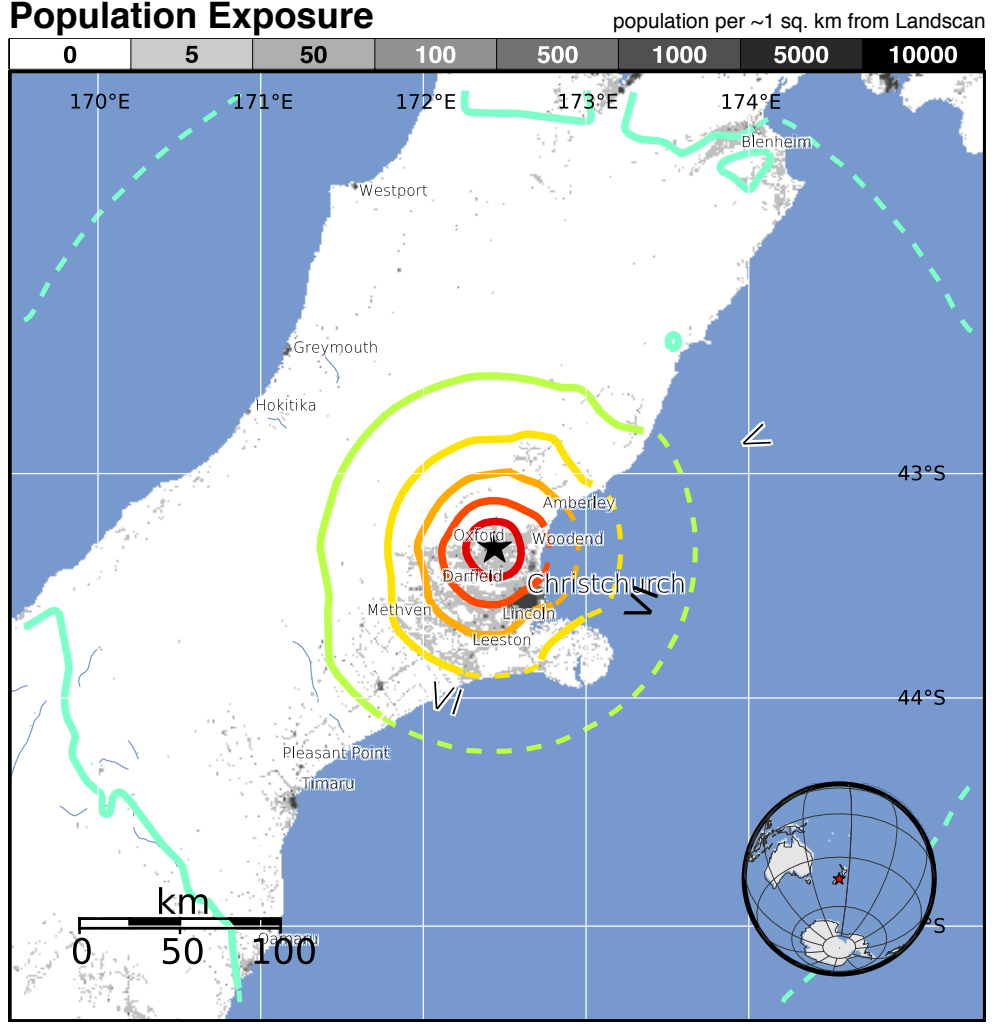

PAGER content is automatically generated, and only considers losses due to structural damage. Limitations of input data, shaking estimates, and loss models may add uncertainty.

http://earthquake.usgs.gov/pager
Overall, the population in this region resides in structures that are highly resistant to earthquake shaking, though some vulnerable structures exist. The predominant vulnerable building types are light wood frame and concrete/cinder block masonry construction.

Historical Earthquakes (with MMI levels):

\begin{tabular}{|lrlcr|}
\hline $\begin{array}{l}\text { Date } \\
\text { (UTC) }\end{array}$ & \multicolumn{2}{c}{$\begin{array}{c}\text { Dist. Mag. } \\
(\mathbf{k m})\end{array}$} & $\begin{array}{c}\text { Max } \\
\text { MMI(\#) }\end{array}$ & $\begin{array}{r}\text { Shaking } \\
\text { Deaths }\end{array}$ \\
\hline $1994-06-19$ & 68 & 5.9 & VIII(12) & 0 \\
$1984-06-24$ & 146 & 6.1 & VIII(17) & 0 \\
$1990-02-10$ & 118 & 6.0 & VIII(62) & 0 \\
\hline
\end{tabular}

\section{Selected City Exposure}

\begin{tabular}{|lr|}
\hline MMI City & Population \\
\hline IX Oxford & $2 \mathrm{k}$ \\
IX Woodend & $3 \mathrm{k}$ \\
IX Christchurch & $364 \mathrm{k}$ \\
IX Rolleston & $3 \mathrm{k}$ \\
VIII Burnham & $1 \mathrm{k}$ \\
VIII Amberley & $1 \mathrm{k}$ \\
V Timaru & $28 \mathrm{k}$ \\
V Blenheim & $27 \mathrm{k}$ \\
V Nelson & $59 \mathrm{k}$ \\
IV Lower Hutt & $101 \mathrm{k}$ \\
IV Wellington & $382 \mathrm{k}$ \\
\hline bold cities appear on map & $(\mathrm{k}=\mathrm{x} 1000)$
\end{tabular}

Event ID: us2010atbj

Figure 14. Loss estimates produced by operational PAGER system after the 2010 Darfield, New Zealand, earthquake. 


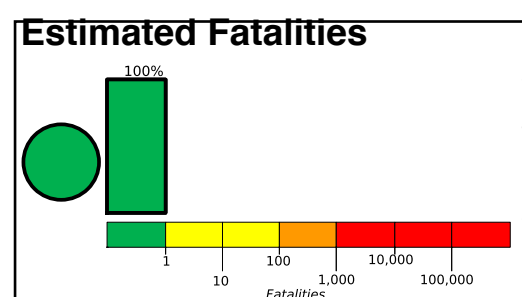

Red alert level for economic losses. Extensive damage is probable and the disaster is likely widespread. Estimated economic losses are international level response.

Green alert level for shaking-related fatalities. There is a low likelihood of casualties.

Created: 3 weeks, 0 days after earthquake

\section{Estimated Population Exposed to Earthquake Shaking}

Estimated Economic Losses

\begin{tabular}{|c|c|c|c|c|c|c|c|c|c|c|}
\hline \multicolumn{2}{|c|}{$\begin{array}{l}\text { ESTIMATED POPULATION } \\
\text { EXPOSURE }(k=x 1000)\end{array}$} & $--^{*}$ & $2 \mathrm{k}^{*}$ & $129 \mathrm{k}^{*}$ & $86 k$ & $139 \mathrm{k}$ & $298 \mathrm{k}$ & $20 \mathrm{k}$ & $2 k$ & 0 \\
\hline \multicolumn{2}{|c|}{$\begin{array}{l}\text { ESTIMATED MODIFIED } \\
\text { MERCALLI INTENSITY }\end{array}$} & I & |I-III & IV & V & VI & VII & VIII & IX & $\mathrm{X}+$ \\
\hline \multicolumn{2}{|c|}{ PERCEIVED SHAKING } & Not felt & Weak & Light & Moderate & Strong & Very Strong & Severe & Violent & Extreme \\
\hline \multirow{2}{*}{$\begin{array}{l}\text { POTENTIAL } \\
\text { DAMAGE }\end{array}$} & $\begin{array}{l}\text { Resistant } \\
\text { Structures }\end{array}$ & none & none & none & V. Light & Light & Moderate & Moderate/Heavy & Heavy & V. Heavy \\
\hline & $\begin{array}{l}\text { Vulnerable } \\
\text { Structures }\end{array}$ & none & none & none & Light & Moderate & Moderate/Heavy & Heavy & V. Heavy & V. Heavy \\
\hline
\end{tabular}

\section{Population Exposure}

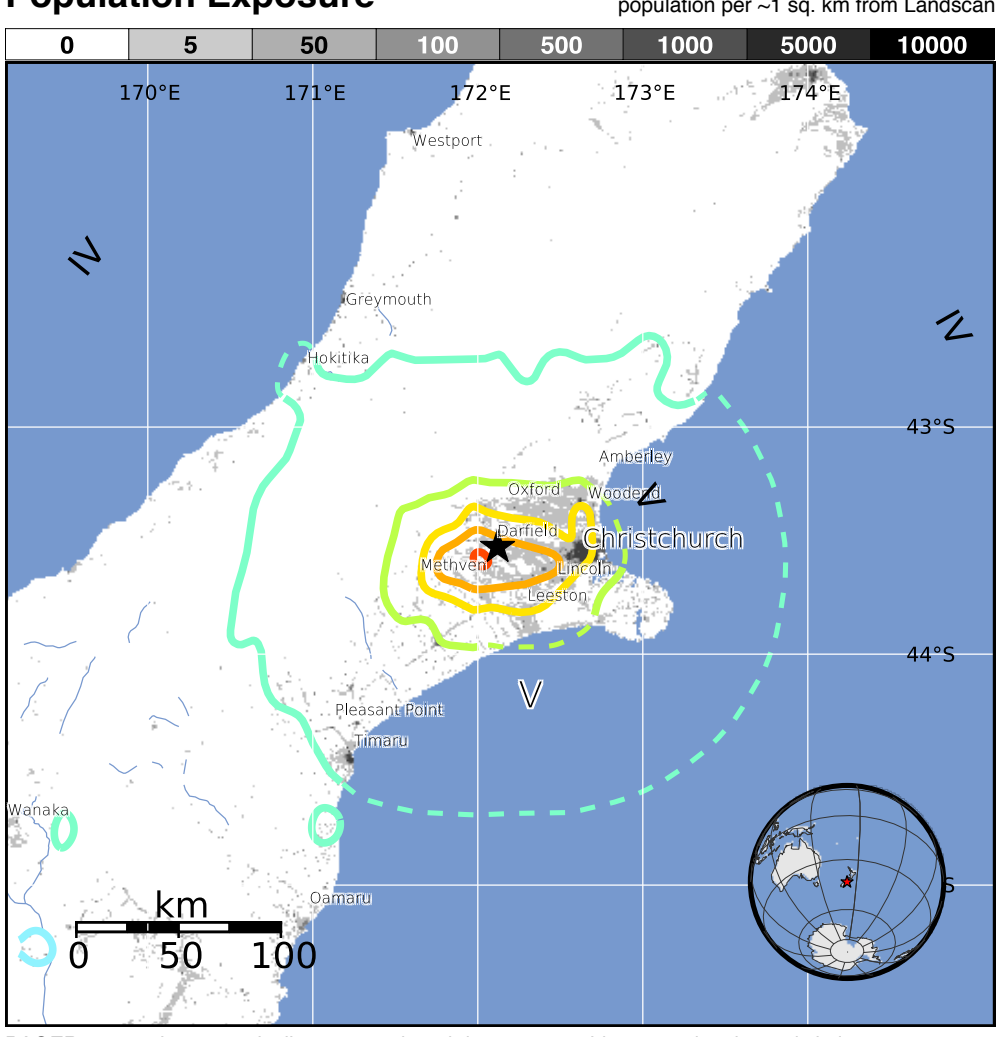

PAGER content is automatically generated, and does not consider secondary hazards in loss http://earthquake.usgs.
Structures:

Overall, the population in this region resides in structures that are highly resistant to earthquake shaking, though some vulnerable structures exist.

Historical Earthquakes (with MMI levels):

\begin{tabular}{|lrl|r|r|}
\hline Date & \multicolumn{2}{c}{$\begin{array}{l}\text { Dist. Mag. } \\
\text { (km) }\end{array}$} & $\begin{array}{c}\text { Max } \\
\text { MMI(\#) }\end{array}$ & $\begin{array}{r}\text { Shaking } \\
\text { Deaths }\end{array}$ \\
\hline $1994-06-19$ & 56 & 5.9 & VIII(12) & 0 \\
$1984-06-24$ & 117 & 6.1 & VIII(18) & 0 \\
$1990-02-10$ & 147 & 6.0 & VIII(61) & 0 \\
\hline
\end{tabular}

\section{Selected City Exposure}

\begin{tabular}{|c|c|}
\hline MMI City & Population \\
\hline VIII Rolleston & \\
\hline VIII Burnham & \\
\hline VII Darfield & 2 \\
\hline VII Woodend & \\
\hline VI Leeston & 1 \\
\hline VI Christchurch & $364 k$ \\
\hline V Timaru & 28 \\
\hline IV Oamaru & 13 \\
\hline IV Greymouth & 9 \\
\hline III Blenheim & 27 \\
\hline III Wanaka & 4 \\
\hline
\end{tabular}

Event ID: us2010atb]

Figure 15. Loss estimates produced by operational PAGER system weeks after the 2010 Darfield, New Zealand, earthquake using revised shaking hazard estimates with finite fault model. 


\section{Limitations}

Regional economic exposure estimated at each intensity level using the per capita GDP and the total population exposed at that level has certain drawbacks. It may not be representative of true physical exposure for certain areas where the actual population density and the scale of economic activities are poorly correlated with each other. Also, the assumption of uniform per capita GDP in a given year throughout the country, as well as a stationary exposure correction factor $\alpha$ due to limited available data, can add to these deficiencies. For example, we do not correct the economic exposure separately for areas of high industrial activities versus those of low economic activity. Similarly, the limitations of the dataset do not permit us to account for the high disparity of growth between urban and rural areas in certain countries. In the future, it may be possible to improve the empirically-estimated economic exposure through the inclusion of finer resolution (at $\sim 1 \mathrm{sq} \mathrm{km}$ grid) per capita GDP estimates available through the Natural Hotspot study (Dilley and others, 2005).

In addition, PAGER loss estimation is also subject to additional uncertainties or inaccuracies within the input datasets, such as the LandScan population database, shaking hazard estimates obtained from the ShakeMap system, estimates of per capita GDP derived for certain countries, and the often uncertain economic losses reported for historical earthquakes in the existing catalog.

Any systematic uncertainty due to these factors may be included in the estimation of the uncertainty parameter $\zeta$ obtained using equation 8; however, any unaccounted-for uncertainties within the input dataset or inaccuracies associated with the earthquake source parameters can result in significant under or over-estimation of losses. 


\section{Summary and Conclusions}

PAGER, through its newly devised alert system (Wald and others, 2011), aims to inform humanitarian aid decisions in the hours or days after an earthquake and before first-hand, ground-truth observations are available to assess the true scope of humanitarian needs. The investigation presented here provides a strategy to rapidly estimate the economic consequences of significant earthquakes anywhere in the world commensurate with the requisite order-ofmagnitude accuracy needed for automated alerting.

The proposed approach bypasses these requirements yet appears to be relatively robust for countries where data from a sufficient number of past, damaging earthquakes are available. Nevertheless, the empirical approach is not intended to replace or supersede the detailed inventory-based PAGER loss models that have been developed based on physical inventory and some knowledge of the seismic vulnerability where data is available. The approach presented here is currently used within the operational PAGER system to rapidly assess the economic impacts from global earthquakes.

The economic loss estimates obtained using the empirical model are approximate and should only be considered within the scope of possible rapid response action and quick decision-making in terms of alerting and resource activation.

\section{Acknowledgments}

This investigation directly benefited from the historical loss data made available through NatCatSERVICE of Munich Reinsurance by Dirk Hollnack and Angelika Wirtz. Other online data sources include the United Nations Statistical Service and the World Bank. The Global Earthquake Model (GEM) Secretariat is thanked for its support during the early phases of this investigation. David Perkins, Robert Wesson, and Margaret Hopper are thanked for their 
constructive reviews and thoughtful comments, which benefited this manuscript. Mike Hearne performed the software implementation of economic model within the PAGER system.

\section{References Cited}

Allen, T.I., Wald, D.J., Earle, P.S., Marano, K.D., Hotovec, A.J., Lin, K. W. and Hearne, M. J., 2009a, An Atlas of ShakeMaps and population exposure catalog for earthquake loss modeling: Bulletin of Earthquake Engineering, v. 7, p. 701-718.

Allen, T.I., Marano, K.D., Earle, P.S., Wald, D.J., 2009b, PAGER-CAT—a composite earthquake catalog for calibrating global fatality models: Seismological Research Letters, v. 80, no. 1, p. 57-62. doi:10.1785/ gssrl.80.1.57

Bhaduri, B., Bright, E., Coleman, P. and Dobson, J., 2002, LandScan-Locating people is what matters: Geoinformatics, v. 5, no. 2, p. 34-37.

Brookeshire, D.S., Chag, S.E., Cochrane, H., Olson, R.A., Rose, A. and Steenson J., 1997, Direct and indirect economic losses from earthquake damage: Earthquake Spectra, v. 13 , no. 4 , p. $683-701$.

Chan, L.S., Chen, Y., Chen, Q.F., Liu, J., Dong, W. and Shah, H., 1998, Assessment of global loss based on macroeconomic indicators: Natural Hazards, v. 17, p. 269-283.

Chen Yong, Chen, Qi-Fu and Chen, L., 2001, Vulnerability analysis in earthquake loss estimate: Natural Hazards, v. 23, p. 349-364.

Dilley, M., Chen, R.S., Deichmann, U., Lerner-Lam, A.L., Arnold, M., Agwe, J., Buys, P., Kjekstad, O., Bradfield, L. and Yetman, G., 2005, Natural Disaster Hotspots-A Global Risk Analysis: Synthesis Report, last accessed May 3, 2010, at http://sedac.ciesin.columbia.edu/hazards/hotspots/synthesisreport.pdf

Dunbar, P., Bilham, R., and Laituri, M., 2002, Earthquake loss estimation for India based on macroeconomic indicators, in Beer, T., and Ismail-Zadeh, A., eds., Risk science and sustainability - Science for reduction of risk and sustainable development of society: Dordrecht, Kluwer Academic Publishers, p. 163-180.

Federal Emergency Management Agency, 2006, HAZUS-MH MR2 Technical Manual: Washington, D.C., Federal Emergency Management Agency, last accessed August 22, 2008, at http://www.fema.gov/plan/prevent/hazus/hz_manuals.shtm.

Jaiswal, K.S., Wald, D.J. and Hearne M.J., 2009, Estimating casualties for large earthquakes worldwide using an empirical approach: U.S. Geological Survey Open-File Report 2009-1136, 83 p. (Also available at http://pubs.usgs.gov/of/2009/1136/.)

Kircher C.A., Seligson, H.A., Bouabid, Jawhar and Morrow, Guy, 2006, When the Big One Strikes Again- Estimated Losses due to a repeat of the 1906 San Francisco earthquake: Earthquake Spectra, v. 22, no. 2, p. 297-339. 
NatCatSERVICE, 2008, Natural catastrophes worldwide 1980 - 2008, Münchener

Rückversicherungs-Gesellschaft, Geo Risks Research (data made available through GEM Foundation, Pavia Italy).

Seligson, H.A. and Eguchi, R.T., 2005, The true cost of earthquake disasters-An updated tabulation of losses for the 1994, Northridge earthquake, in International Symposium on Earthquake Engineering Commemorating the Tenth Anniversary of the 1995 Kobe Earthquake, Kobe, Japan, 2005, Proceedings: Kobe, Japan, International Symposium on Earthquake Engineering, 6 p.

Wald, D.J., Earle, P.S., Allen, T.I., Jaiswal, K.S., Porter, K.A., and Hearne, M.J., 2008, Development of the U.S. Geological Survey's PAGER system (Prompt Assessment of Global Earthquakes for Response), in World Conference on Earthquake Engineering, $14^{\text {th }}$, Beijing, China, October 2008, Proceedings: Beijing, China, World Conference on Earthquake Engineering, Paper No. 10-0008.

Wald, D.J., Jaiswal, K.S. Marano, K.D., and Bausch, Doug, 2011, An Earthquake Impact Scale: Natural Hazards Review, posted ahead of print at http://dx.doi.org/10.1061/(ASCE)NH.1527-6996.0000040.

World Bank, 2006, Where is the wealth of nations? Measuring Capital for the 21st Century: World Bank, 1818 H Street, NW, Washington, DC 20433. 


\section{Appendix - I}

This is an electronic supplement to this report made available at http://pubs.usgs.gov/of/2011/1116/ 